\title{
Wearing masks to reduce the spread of respiratory viruses: a systematic evidence mapping
}

\author{
Yanfei Li ${ }^{1,2,3,4 \#}$, Zhipeng Wei ${ }^{1,2,3,4,5 \#}$, Jingyun Zhang $^{5}$, Rui Li $^{1,2,3,4}$, Huijuan $\mathbf{L i}^{1,2,3,4}$, Liujiao Cao ${ }^{1,2,3,4}$, \\ Liangying Hou ${ }^{1,2,3,4}$, Weiyi Zhang ${ }^{1,2,3,4}$, Nan Chen ${ }^{1,2,3,4}$, Kangle Guo ${ }^{1,2,3,4}$, Xiuxia Li ${ }^{1,2,3,4}$, Kehu Yang ${ }^{1,2,3,4,5} \wedge$
}

${ }^{1}$ Evidence Based Social Science Research Center/Health Technology Assessment Center, School of Public Health, Lanzhou University, Lanzhou, China; ${ }^{2}$ Key Laboratory of Evidence Based Medicine and Knowledge Translation of Gansu Province, Lanzhou University, Lanzhou, China; ${ }^{3}$ WHO Collaborating Centre for Guideline Implementation and Knowledge Translation, Lanzhou University, Lanzhou, China; ${ }^{4}$ Chinese GRADE Center, Lanzhou University, Lanzhou, China; ${ }^{5}$ Evidence-Based Medicine Center, School of Basic Medical Sciences, Lanzhou University, Lanzhou, China Contributions: (I) Conception and design: K Yang, Y Li, Z Wei, X Li; (II) Administrative support: X Li, K Yang; (III) Provision of study materials or patients: Y Li, Z Wei, J Zhang, R Li; (IV) Collection and assembly of data: Y Li, Z Wei, J Zhang, R Li, H Li, L Cao, L Hou, W Zhang, N Chen, K Guo; (V) Data analysis and interpretation: Y Li, Z Wei, J Zhang, R Li, H Li, L Cao; (VI) Manuscript writing: all authors; (VII) Final approval of manuscript: all authors.

\#These authors contributed equally to this work.

Correspondence to: Kehu Yang. Evidence-Based Medicine Center, Lanzhou University, 199 Donggang West Road, Lanzhou, China.

Email: kehuyangebm2006@126.com; Xiuxia Li. Evidence Based Social Science Research Center/Health Technology Assessment Center, Lanzhou University, 199 Donggang West Road, Lanzhou, China. Email: lixiuxia@lzu.edu.cn.

\begin{abstract}
Since the outbreak of coronavirus disease in 2019, the controversy over the effectiveness, safety, and enforceability of masks used by the public has been prominent. This study aims to identify, describe, and organize the currently available high-quality design evidence concerning mask use during the spread of respiratory viruses and find evidence gaps. Databases including PubMed, Cochrane Library, Web of Science, EMBASE, WHO International Clinical Trials Registry Platform (ICTRP), clinical trial registry, gray literature database, and reference lists of articles were searched for relevant randomized controlled trials (RCTs) and systematic reviews (SRs) in April 2020. The quality of the studies was assessed using the risk of bias tool recommended by the Cochrane Handbook Version 5.1.0 and the Assessment of Multiple Systematic Reviews (AMSTAR 2) tool. A bubble plot was designed to display information in four dimensions. Finally, twenty-one RCTs and nine SRs met our inclusion criteria. Most studies were of "Low quality" and focused on healthcare workers. Six RCTs reported adverse effects, with one implying that the cloth masks reuse may increase the infection risk. When comparing masks with usual practice, over 70\% RCTs and also SRs showed that masks were "beneficial" or "probably beneficial"; however, when comparing N95 respirators with medical masks, 75\% of SRs showed "no effect", whereas 50\% of RCTs showed "beneficial effect". Overall, the current evidence provided by high-quality designs may be insufficient to deal with a second impact of the pandemic. Masks may be effective in interrupting or reducing the spread of respiratory viruses; however, the effect of an N95 respirator or cloth masks versus medical masks is unclear. Additional high-quality studies determining the impact of prolonged mask use on vulnerable populations (such as children and pregnant women), the possible adverse effects (such as skin allergies and shortness of breath) and optimal settings and exposure circumstances for populations to use masks are needed.
\end{abstract}

Keywords: COVID-19; cloth mask; evidence mapping; gap maps; mask

Submitted Oct 04, 2020. Accepted for publication Feb 28, 2021.

doi: 10.21037/atm-20-6745

View this article at: http://dx.doi.org/10.21037/atm-20-6745

\footnotetext{
^ ORCID: 0000-0001-7864-3012.
} 


\section{Introduction}

On December 31, 2019, a novel coronavirus was reported for the first time in Wuhan, China. The virus is now named by the World Health Organization (WHO) as severe acute respiratory syndrome coronavirus 2 (SARSCoV-2). On March 11, 2020, WHO characterized the coronavirus disease 2019 (COVID-19) outbreak as a pandemic (1). There is a lack of specific antiviral treatment or available vaccines that have proven to be effective for this new viral disease (2). The infected people primarily rely on symptomatic treatment and supportive care $(3,4)$. Authorities of most countries have recommended measures such as maintaining social distancing and washing hands, which are considered extremely important measures to reduce the risk of infection (5-7). However, given the cultural differences or absence of high-quality evidence, controversies over the effectiveness, safety, and enforceability of masks worn by the public were prominent in the early stages of this global epidemic.

Most of the available research on masks focused on healthcare workers and household contacts (individuals living in a household with patients with a respiratory virus infection) (8), and data on other populations are scarce $(9,10)$. Furthermore, there are contradictions in the research results between different study settings (such as hospitals, community, and laboratory), which prevents the decision makers from making appropriate judgments (11). Therefore, our study focused on randomized controlled trials (RCTs) of non-laboratory research or systematic reviews (SRs) including RCTs (which met our inclusion criteria of RCTs). This is because non-laboratory studies might generalize to a wider population, and RCTs and SRs, as high-quality study designs, have the highest possible quality of evidence and are an important reference value for decision makers in general $(12,13)$. In addition, the outcomes that we mainly focused on included influenza-like illness (ILI), laboratory-confirmed respiratory infection, and self-reported infection symptoms, which are the most common judgment indicators with regard to the spread of respiratory viruses (11). The ILI was usually defined as fever $>38^{\circ} \mathrm{C}$ and one or more of the following symptoms: nasal discharge/congestion, cough, conjunctivitis, respiratory distress (tachypnea, retractions), sore throat, and new seizure (8).

In addition, medical and public health professionals are concerned that the improper mask use may cause other unfavorable effects (14), policymakers also urgently need relevant high-quality evidence to support policy making. In a previous study, it was suggested that many COVID19-related studies are poorly designed, merely adding to the COVID-19 noise (13). Therefore, it is necessary to comprehensively and systematically collect, present, and analyze current high-quality design studies. Evidence mapping (EM) is a type of comprehensive evidence-based research method that systematically and rapidly collects, evaluates, organizes, and presents existing evidence $(15,16)$. EM presents a visual overview of existing evidence in a certain research field, and clarifies the characteristics of the studies in this field from multiple dimensions (such as the types of interventions, the research population, conclusions of the research, etc.), thereby providing systematic evidence support for decision makers (17). Furthermore, EM can also help identify evidence gaps (18). Therefore, EM can be the first step to conduct SRs or the framework to inform policy development (19). However, EM does not provide details on the generation of research results or incorporate meta-analytic techniques for pooling effect estimates, which is currently perhaps the most controversial point in EM methodology (20). Currently, no EM study, based on related RCTs and SRs, exists that presents and assesses the effectiveness and adverse effects of wearing masks to control the spread of respiratory viruses. Thus, in this study, we aimed to identify, describe, and organize currently available high-quality design evidence for mask use during the spread of respiratory viruses through an EM approach and identify gaps in evidence.

We present the following article in accordance with the PRISMA reporting checklist (available at http://dx.doi. org/10.21037/atm-20-6745).

\section{Methods}

\section{Literature search}

We searched four databases (Web of Science, Cochrane Library, EMBASE, and PubMed) on April 9, 2020. Major search terms and strategies (Appendix 1) were as follows: ("Mask"[Mesh] OR mask OR facemask OR masks OR respirator OR N95 OR FFP2 OR "personal protective equipment" OR protective devices) AND ("Respiratory Tract Infections"[Mesh] OR ILI OR infect OR influenza OR MERS OR "Middle East respiratory syndrome" OR pandemic OR parainfluenza OR "respiratory disease" OR "respiratory illness" OR "respiratory infection" OR "respiratory hygiene" OR "respiratory virus" OR SARS OR 
SARS-CoV-2 OR COVID-19 OR "severe acute respiratory syndrome" OR virus) AND ("random*" OR "blind*" OR "singleblind" " OR "doubleblind*" OR "trebleblind*" OR "tripleblind"”). Moreover, the WHO International Clinical Trials Registry Platform (ICTRP) Search Portal, clinical trial registry, reference lists of articles, and gray literature were searched on April 27, 2020.

\section{Inclusion and exclusion criteria}

RCTs and SRs including RCTs that evaluated the mask use as an intervention against the spread of respiratory viruses were included in the study. The inclusion criteria were as follows: (I) no restriction for participants; (II) inclusion of mask intervention the treatment or intervention group (e.g., face mask, N95 respirator, and/or medical/surgical masks); and (III) inclusion of usual practice (e.g., education without the face mask use) or medical/surgical masks in the control groups. Furthermore, when several SRs published by the same team were identified, the most recent publication was considered. The following studies were excluded: (I) duplicate reports of a study; (II) studies with insufficient data (e.g., conference abstracts); (III) non-human studies; and (IV) laboratory studies.

\section{Study selection and data extraction}

Literature screening and data extraction were performed by two independent reviewers. Different views between the two reviewers were discussed and resolved by a third independent reviewer. EndNote X9 software was used to remove duplicates. Subsequently, the title and abstract of preliminary included studies were screened by two independent reviewers. For studies that according by both reviewers should be excluded, further screening was not conducted. For studies that according to at least one reviewer should be included or if a definitive decision could not be made, the full text was further screened and the suitability for final inclusion was determined. A predesigned table was designed to conduct data extraction, and general information was extracted about the study, including publication year, the first author, and country. We also included details concerning the type of intervention, population, result, conclusion, study design, and sample size.

\section{Quality assessment}

The tool recommended by the Cochrane Handbook
Version 5.1.0 (21) was used to analyze the risk of bias of the included trials based on the following factors: random sequence generation, incomplete outcome data, allocation concealment, blinding of outcome assessment, selective reporting, blinding of participants and personnel, and other bias. Each item was classified as "Yes" ("low risk of bias"), "No" ("high risk of bias"), or "Unclear" ("moderate risk of bias"). When the risk of bias for all seven factors was assessed as "low risk of bias," the trial was assessed to have an overall "low risk of bias." Accordingly, when one or more of the seven bias factors were assessed as high risk, the trial was assessed to have a "high risk of bias." For other cases, the trial was assessed to have an "unclear risk." Differences in bias assessment were resolved through discussion by two independent reviewers. Furthermore, in some cases, a third reviewer participated in the resolution of differences.

The Assessment of Multiple Systematic Reviews (AMSTAR-2) tool (22) was used to assess the methodological quality of all SRs. AMSTAR 2 consists of 16 items and each item was evaluated using "Yes", "Partial Yes", or "No". The assessment process was conducted online (https://amstar. ca/Amstar_Checklist.php), the overall quality assessment results ("Critically low quality," "Low quality," "Moderate quality", or "High quality") was automatically generated. Two independent reviewers evaluated these items, and differences were resolved by discussion with a third reviewer.

\section{Data synthesis and analysis}

Currently, there is a lack of reporting guidelines or methodological guidance with regard to EM. We are, therefore, based our study on the methodology of Global Evidence Mapping (23), Campbell evidence and gap maps (24), and our previous findings (17) concerning EM and evidence and gap map methodology, and made necessary expansion on this basis $(25,26)$. All authors have fully discussed the extension of each methodology and the construction of the framework of this article. A bubble plot was designed to display information in four dimensions as follows $(27,28)$ : (I) each bubble represents one RCT/SR and different colors represent various research populations; (II) the bubble size represents the sample size/number of RCTs included in this mapping; (III) the rating of authors' conclusions are represented on the $\mathrm{X}$-axis as "beneficial," "probably beneficial," "harmful," "no effect," and "inconclusive"; and (IV) quality assessment is represented on the Y-axis. We observed that some studies $(15,27)$ have made meaningful explorations especially in terms of rating of 


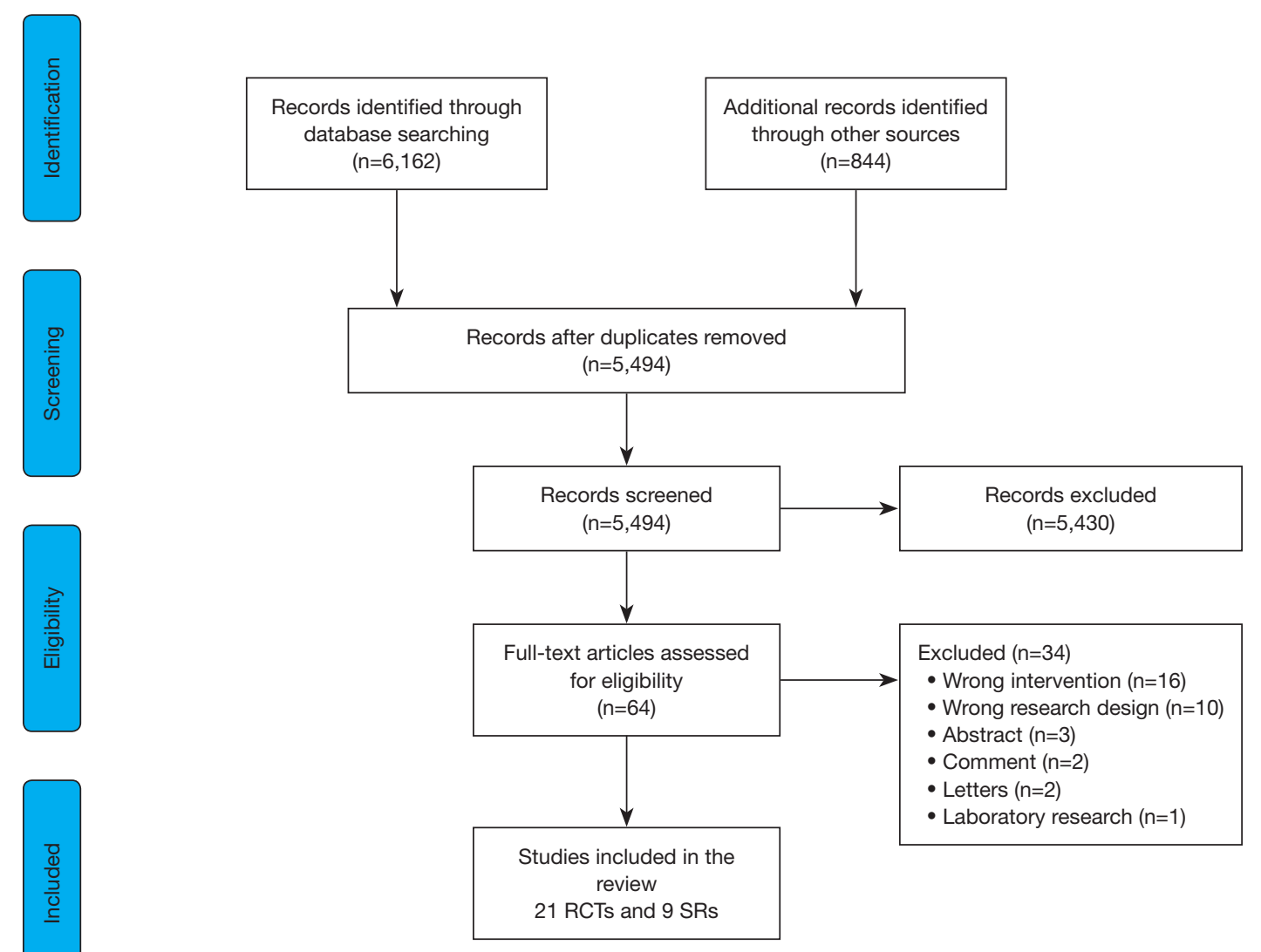

Figure 1 Flow diagram of the literature screening process and results.

the authors' conclusions. Based on these studies, we conducted in-depth discussions and divided the conclusions into five categories considering the descriptions of both the results and conclusions of the included study, in which "beneficial" indicated that the conclusions and results reported a clear beneficial effect without major concerns regarding supporting evidence, "probably beneficial" suggested that the conclusions did not claim firm benefits despite the reported positive treatment effect or the conclusions reported a potential benefits despite the result showing no significant difference, "harmful" suggested that the conclusions and results were reported to be clearly indicative of a harmful effect, "no effect" suggested that the conclusions and results provided evidence of no differences between intervention and comparator, and "inconclusive" suggested that the results of the study were insufficient for the authors to conclude whether the intervention has a definitive or potential effect. Moreover, the judgment indicators mainly were ILI, laboratory-confirmed respiratory infection, or selfreported infection symptoms. In addition, narrative synthesis was conducted for expanding upon mapping to provide more details about the included studies. These included descriptions of the evidence gaps and adverse events.

\section{Results}

\section{Study selection}

As shown in Figure 1, a total of 7,006 studies were initially included; however, of these, 1,512 duplicates were excluded. The titles and abstracts of the remaining 5,494 studies were screened, following which 5,430 studies were deemed unsuitable for inclusion. The full texts of the remaining 64 studies were screened and another 34 articles were excluded (Table S1). Finally, 21 RCTs and nine SRs were included and analyzed.

\section{Study characteristics}

The essential information of the included studies has been shown in Table 1 (Table S2 for a more detailed summary 


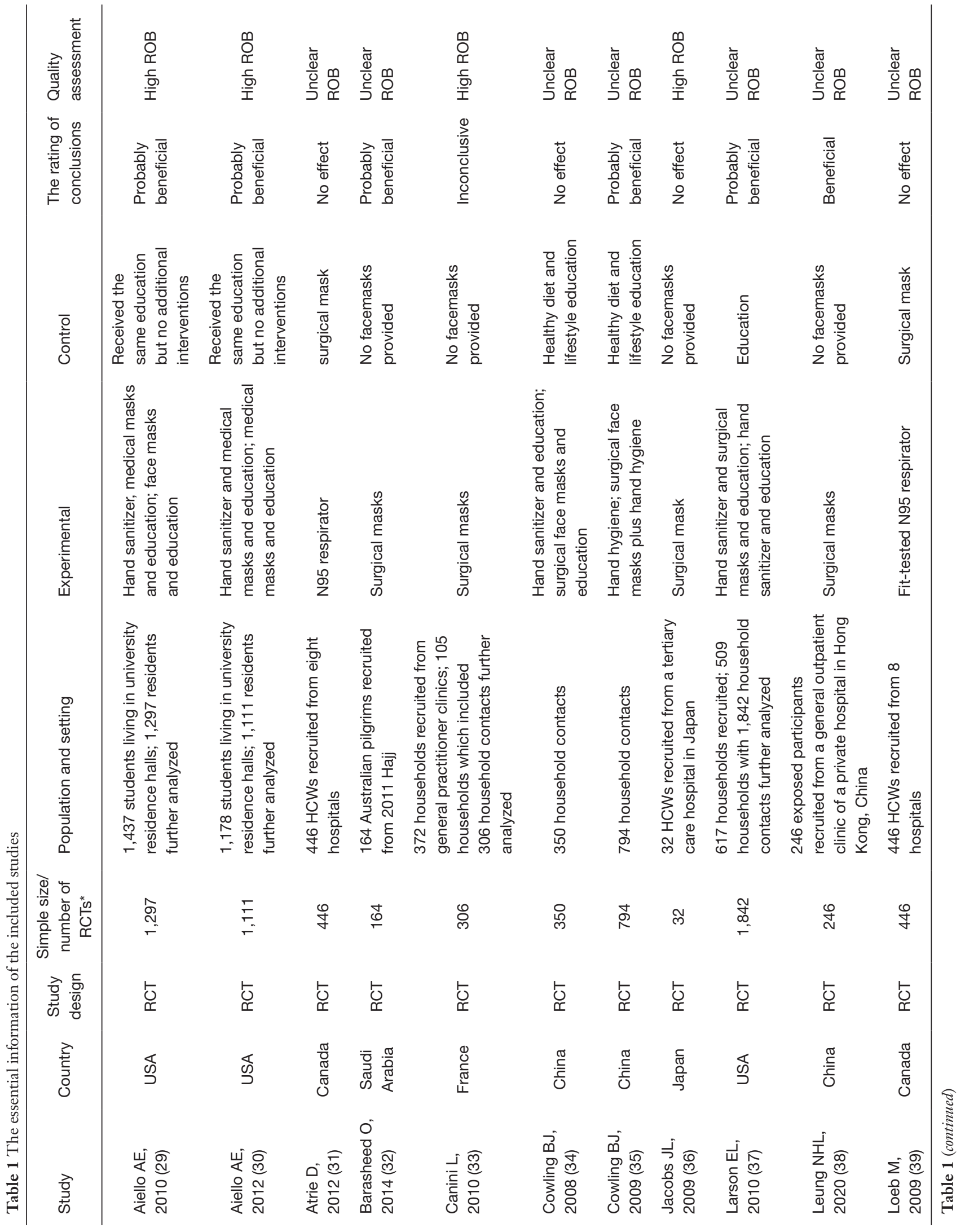




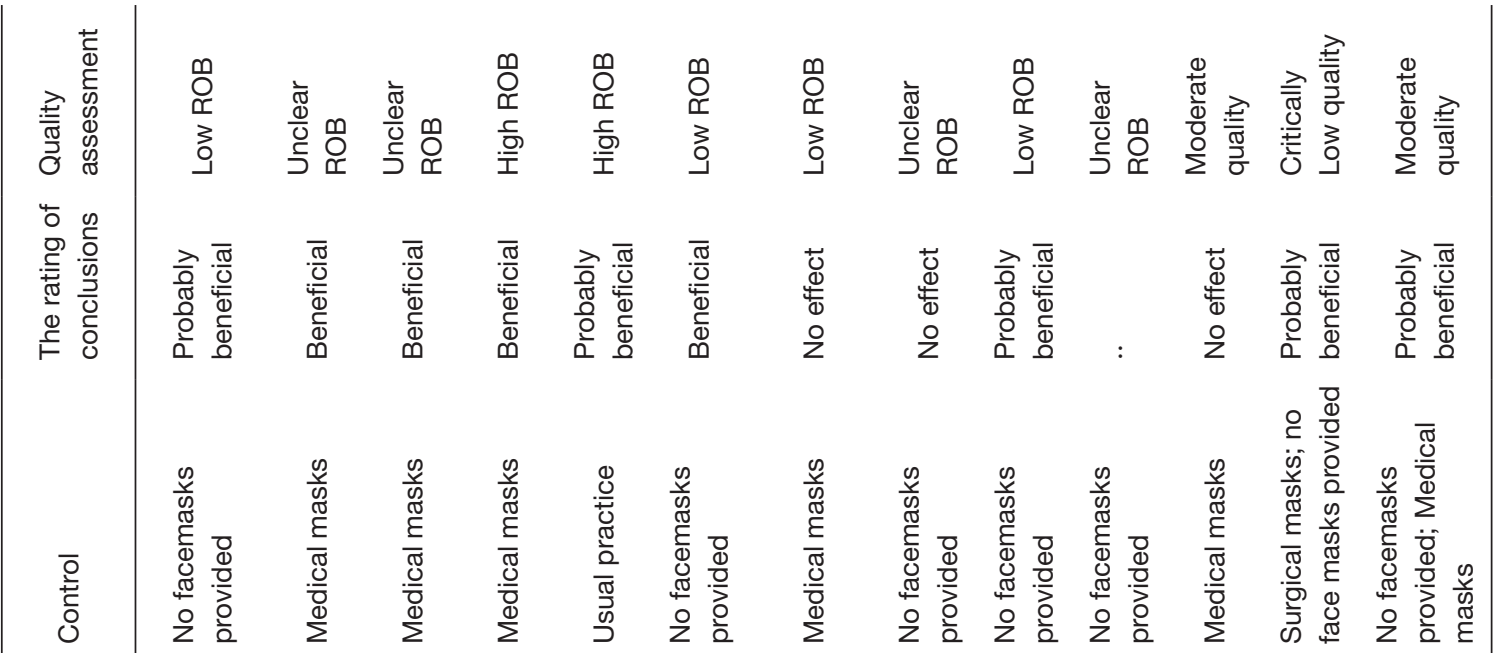

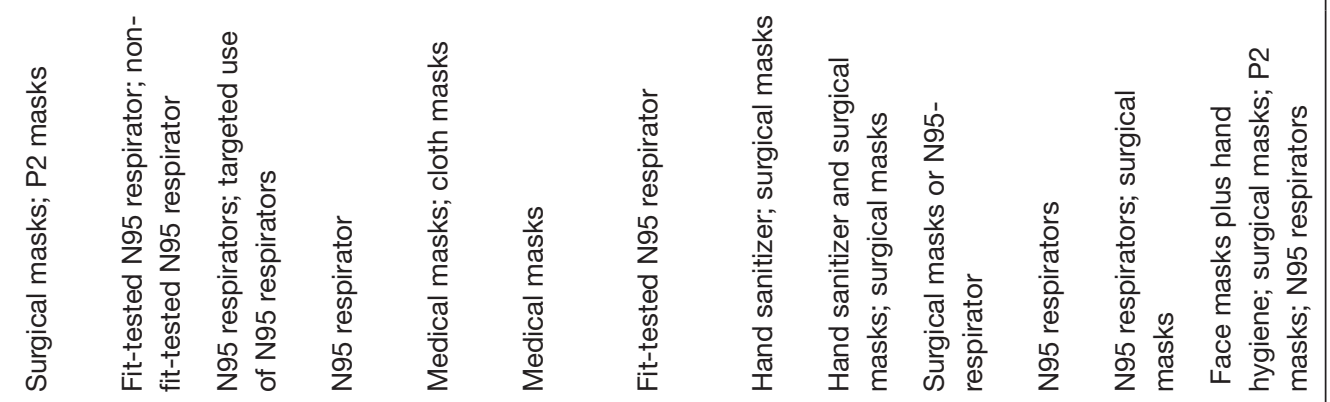

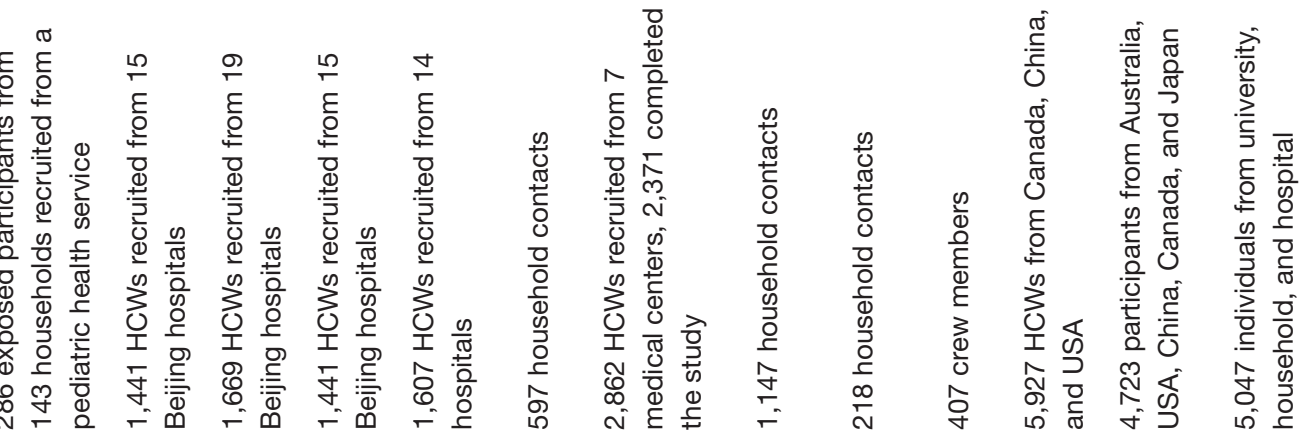

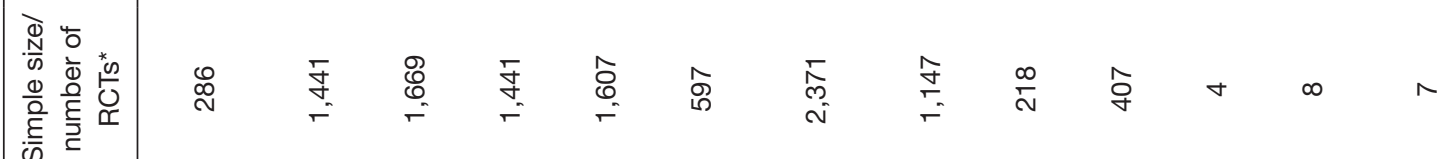

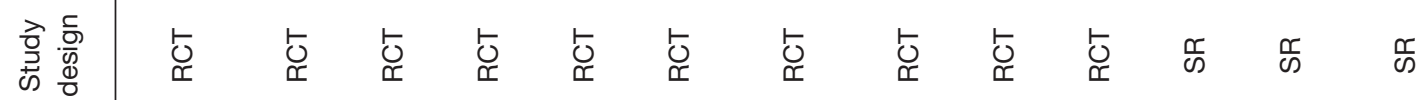

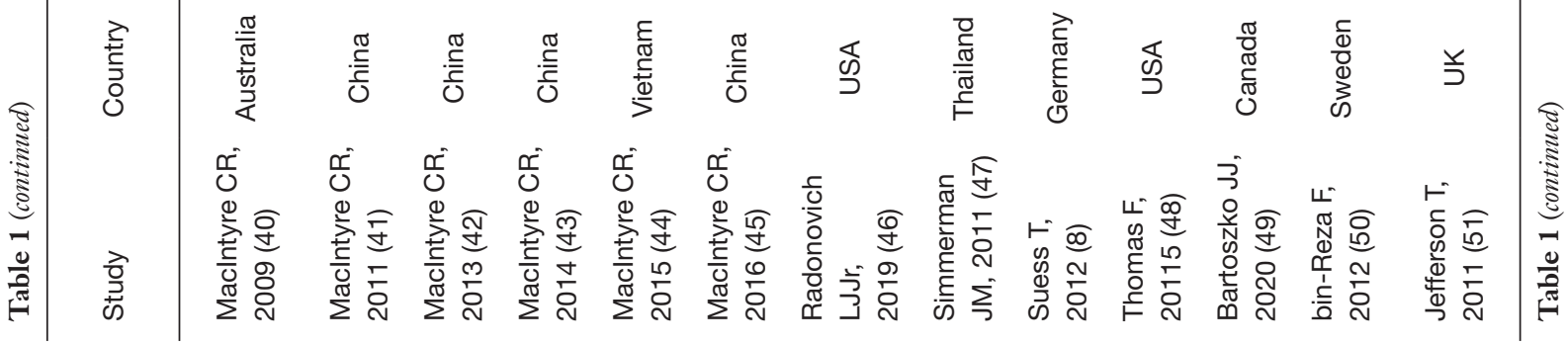




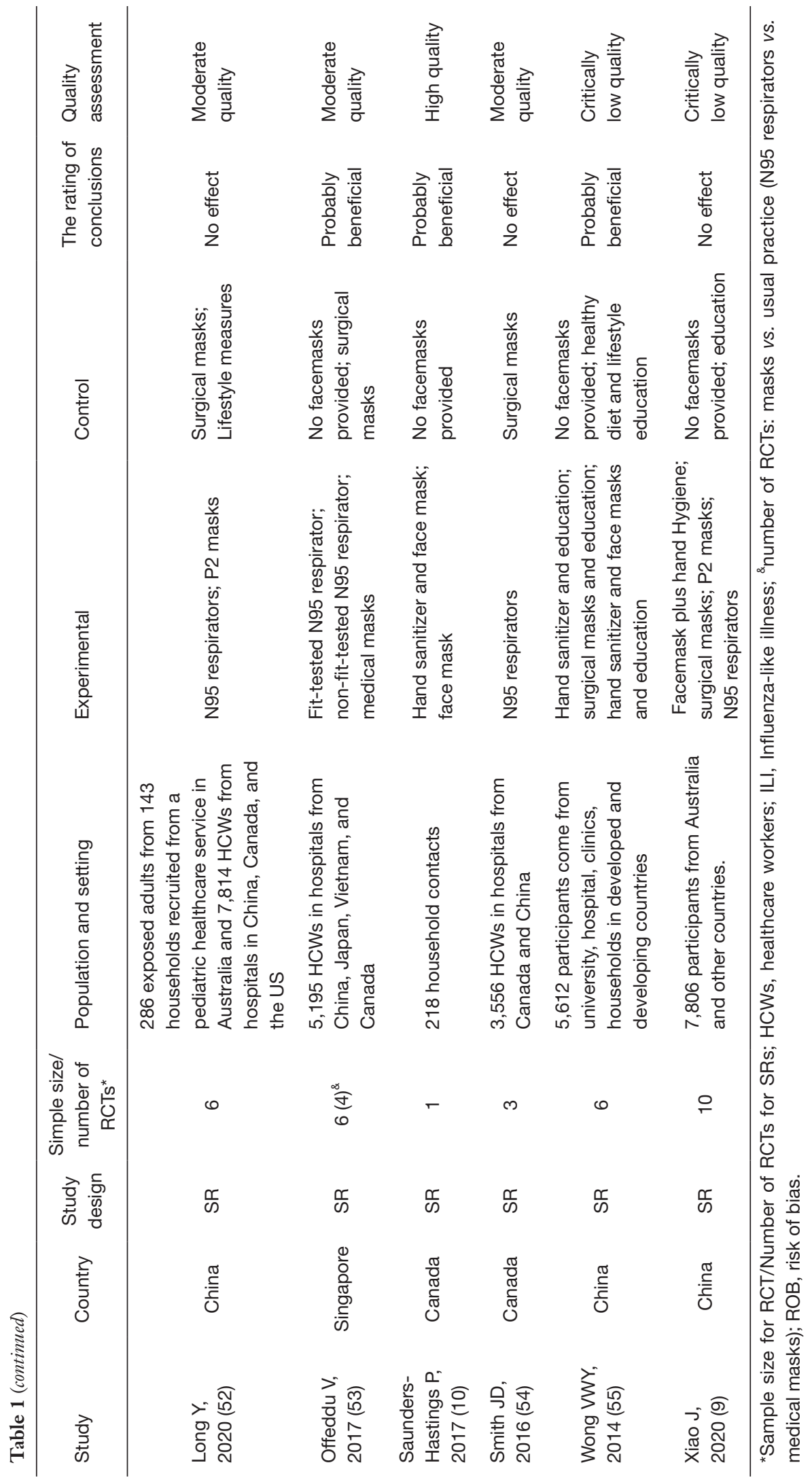




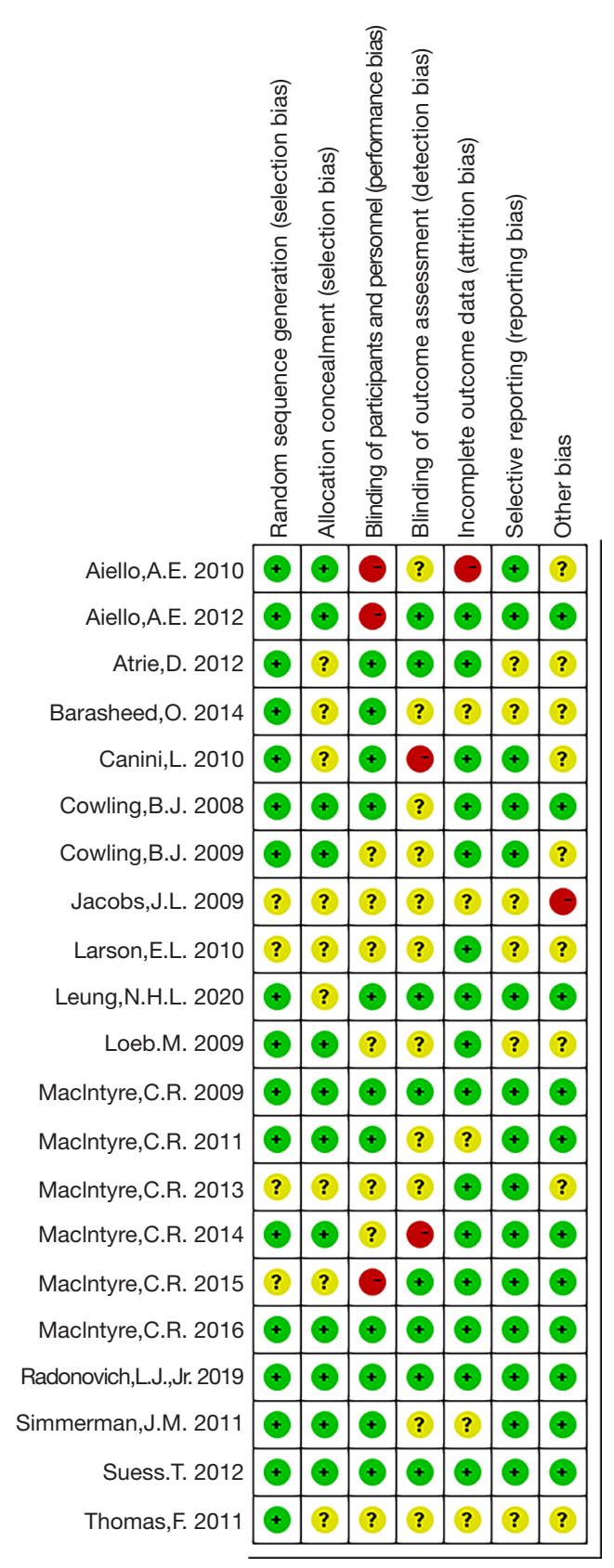

Figure 2 Quality assessment for the 21 included randomized controlled trials.

by PICO). In total, 21 trials evaluating 18,709 individuals were included in our study. Of the selected studies, the highest proportion were conducted in China $(>30 \%, 7 / 21)$, followed by USA $(23.81 \%, 5 / 21)$, Canada $(9.52 \%, 2 / 21)$, Australia $(4.76 \%, 1 / 21)$, France $(4.76 \%, 1 / 22)$, Germany (4.76\%, 1/21), Japan (4.76\%, 1/21), Saudi Arabia (4.76\%, $1 / 21)$, Thailand $(4.76 \%, 1 / 21)$, and Vietnam $(4.76 \%, 1 / 21)$.
The populations in eight trials included healthcare workers $(38.10 \%, 8 / 21)$; seven trials, household contacts $(33.33 \%$, $7 / 21)$; two trials, students $(9.52 \%, 2 / 21)$; two trials, exposed participants $(9.52 \%, 2 / 21)$; one trial, crewmembers $(4.76 \%, 1 / 21)$; and one trial, Australian pilgrims (4.76\%, 1/21). Furthermore, nine SRs were included in our study; of these, three were conducted in China $(33.33 \%)$ and Canada (33.33\%), one in Sweden $(11.11 \%)$, the UK (11.11\%), Australia (11.11\%), and Singapore (11.11\%). The populations in three of these studies included healthcare workers (33.33\%); one, household contacts $(11.11 \%)$, and five, mix populations $(55.56 \%)$.

\section{Quality assessment}

A summary of the risk of bias for each included trial is shown in Figure 2. In the random-sequence generation analysis, over $80 \%(17 / 21)$ of trials described an adequate random-sequence generation process. Over 50\% (12/21) trials described the use of sealed, opaque envelopes for allocation concealment. No one trial was selective in their data reporting. Eight trials had a "low risk of bias" regarding the blinding of outcome assessment and three trials had a "high risk of bias" in terms of blinding of participants. In addition, over $70 \%(15 / 21)$ of trials were found to have a "low risk of bias" in terms of incomplete outcome data. Other bias was detected in one trial.

As shown in Figure 3, according to the evaluation criteria of the latest version of AMSTAR-2, all SRs reported the components of PICO, duplicated coding for study selection and data extraction, and on comprehensive literature search, eight of the remaining items (items 2, 3, 8, 9, 11, 12, 13, and 16) were reported by over $50 \%$ SRs. Only less than $40 \%$ SRs reported Items 7, 10, 14, and 15. In particular, item 7 (provide a list of excluded studies and justify the exclusions) was reported in only one SR. In addition, only one SR (1/9) was assessed to be of "High quality", five SRs (5/9) were assessed to be of "Moderate quality", and three (3/9) SRs were assessed to be of "Critically Low" (Table S3).

\section{Mapping}

As shown in Figure 4, a bubble plot was designed for mapping, and four dimensions were used to visualize the RCTs and SRs (research populations, sample size/number of RCTs, the rating of conclusions, and quality assessment).

\section{Masks $v s$. usual practice}

As shown in Figure 4A, six SRs $(9,10,50,51,53,55)$ evaluated 
1. covering PICO (participants, intervention,

2. following review protocol

3. study design selecti on

4. literature search strategy

5. duplicated coding for study selection

6. duplicated coding for data extraction

7. justification of excluded papers

8. description of included stdies

9. assessment of risk of bias

10. reporting study funding source

11. using appropriate statistical combination method

12. ROB impact on meta-analysis

13. discussing of ROB impact

14. addressing heterogeneity

15. consideration of publication bias

16. reporting conflict of interest

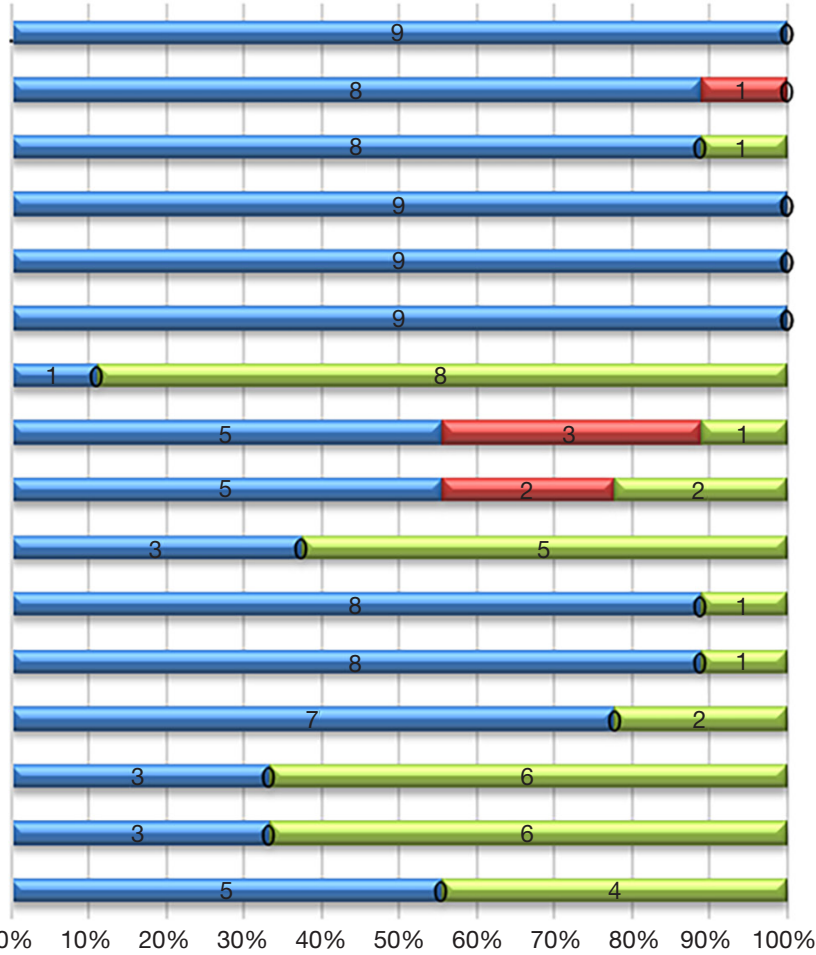

$\square$ Yes

Partial Yes

$\square$ No

Figure 3 Quality assessment for the nine included systematic reviews.

the effects of wearing masks on the interruption or reduction in the spread of respiratory viruses compared with control groups (i.e., with only education and no face masks). Among them, five SRs $(10,50,51,53,55)$ were selected as "probably beneficial" on the map suggestive of the probable effectiveness of regular masks in limiting transmission during pandemics; the effectiveness of masks and respirators in these studies was likely linked to early, consistent, and correct usage. The remaining study (9) showed "no effect" indicative of limited evidence to support the effectiveness of masks. Moreover, three SRs $(9,50,55)$ were classified to be of "critically low quality", two $(51,53)$ of "moderate quality", and one (10) of "high quality". Overall, $83.33 \%$ SRs (5/6, involving 28 RCTs) were included in "beneficial" or "probably beneficial" categories.

As shown in Figure 4B, 14 RCTs $(8,29,30,32-38,40,44,45,47)$ including 9,997 participants researched the effects of wearing masks on the interruption or reduction in the spread of respiratory viruses when compared to the control groups. Among these, two RCTs $(38,45)$ with 843 participants were categorized as "beneficial" indicating that masks were effective in interrupting or reducing the spread of respiratory viruses. Eight RCTs $(8,29,30,32,35,37,40,44)$, including 7,319 participants were categorized as "probably beneficial", thereby indicating that masks may be helpful, and recommended wearing masks to interrupt the spread of respiratory viruses. Furthermore, three RCTs $(34,36,37)$, including 1,529 participants were categorized as "no effect". The remaining RCT (33) including 306 participants was found to be "inconclusive", indicating that there was no sufficient evidence to draw a conclusion based on the research. Moreover, according to the risk of bias tool, three $(8,40,45)$, five $(29,30,33,36,44)$, and six $(32,34,35,37,38,47)$ RCTs were assessed as "low risk of bias," "high risk of bias," and "unclear risk of bias," respectively. In all, $71.43 \%$ RCTs (10/14, including 8162 participants) were classified into "beneficial" or "probably beneficial" categories.

\section{N95 respirators $v s$. medical masks}

As shown in Figure 4A, four SRs (49,52-54) evaluated the effect of N95 respirators on the interruption or reduction of the spread of respiratory viruses compared that with the 


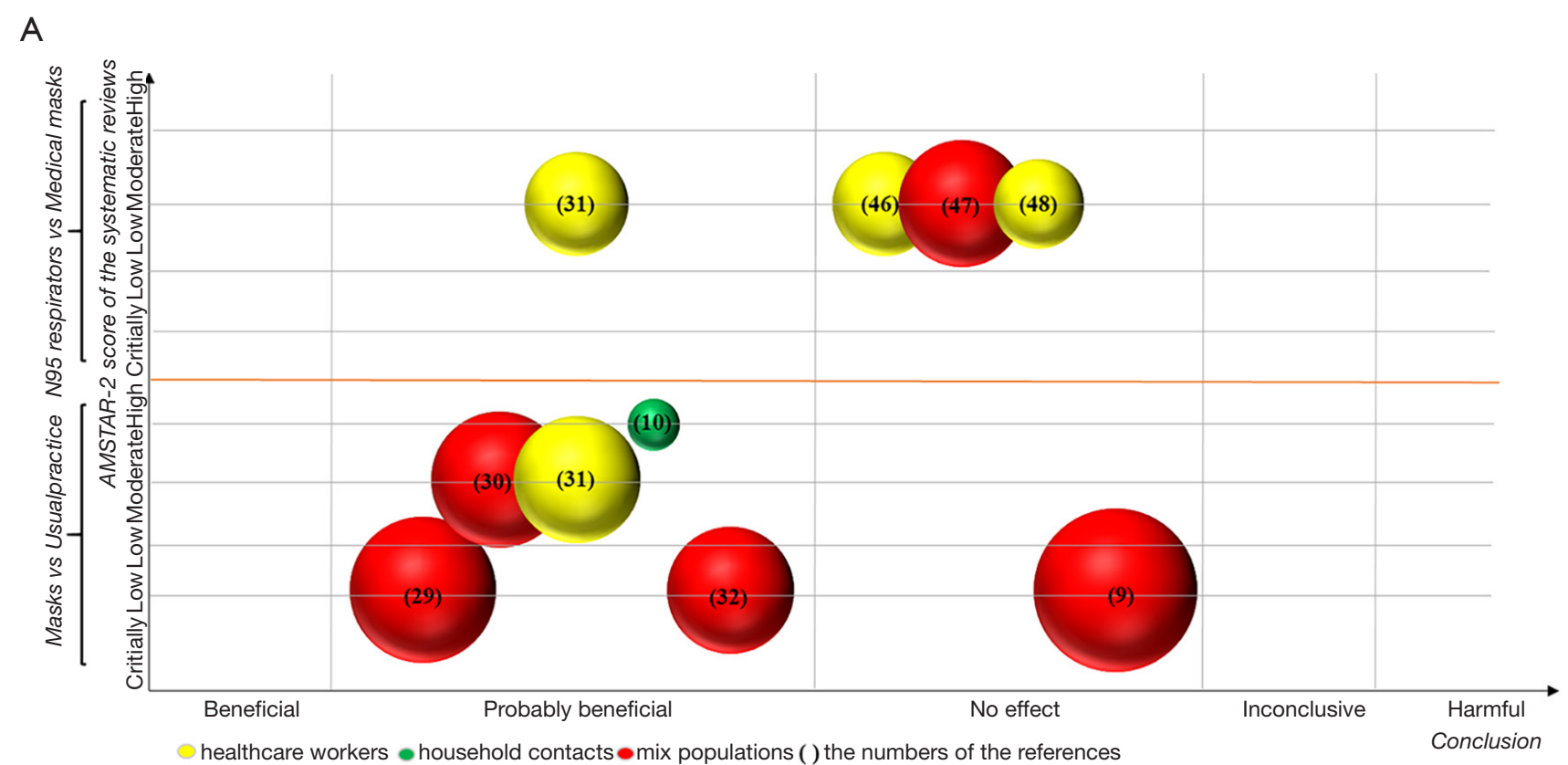

B

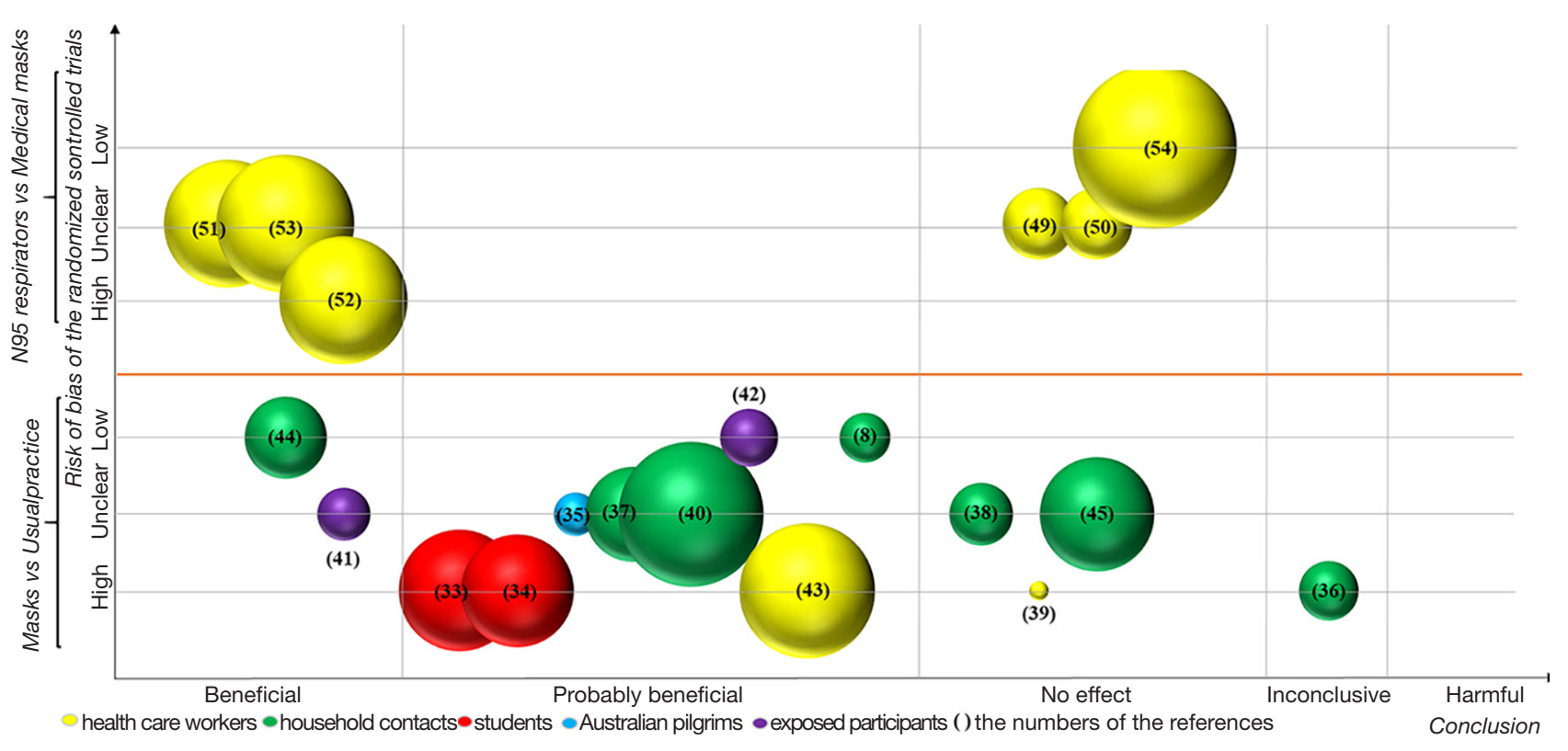

Figure 4 Evidence mapping for mask use during the spread of respiratory viruses.

effect of medical masks. Three SRs were categorized as "no effect," thereby indicating that N95 respirators did not have a better effect compared with medical masks. Furthermore, all four SRs $(49,52-54)$ were assessed as "moderate quality". In all, only $25 \%$ (1/4, involving 4 RCTs) SRs was categorized under "beneficial" or "probably beneficial" categories.
As shown in Figure 4B, six RCTs $(31,39,41-43,46)$ including 7814 participants evaluated the effect of N95 respirator on the interruption or reduction of the spread of respiratory viruses and compared that with the effect of medical masks. Among these, three RCTs (41-43), including 4,551 participants were categorized as "beneficial", thereby suggesting that N95 respirators may be effective for 
interrupting or reducing the spread of respiratory viruses compared with medical masks. Furthermore, three RCTs $(31,39,46)$ including 3,263 participants showed "no effect," indicating similar effects between N95 respirators and medical masks. In addition, one RCT (46) was assessed as "low risk of bias;" one (43), as "high risk of bias;" and four $(31,39,41,42)$, as "unclear risk of bias". Overall, $50 \%$ RCTs (3/6, including 4,551 participants) were classified into "beneficial" or "probably beneficial" categories.

\section{Adverse effects}

Six trials $(8,33,36,44,46,48)$ partially reported possible adverse effects of wearing masks, and showed that the mask groups were more likely to experience headaches during the study period, skin irritation, worsening acne, shortness of breath, and respiratory difficulties. In addition, since masks seem to affect the precise and clear transmission and reception of some aviation terms or instructions (i.e., helipad, fuel, weather) by pilots, flight nurses, layperson, dispatcher, etc., especially when the aircraft's engine is turned on, mask use may adversely affect radio communication (48). Notably, MacIntyre et al. (44) compared the efficacy of cloth masks to that of medical masks in hospital healthcare workers, and showed that participants using cloth masks (cotton, or gauze masks) showed a significantly higher rate of ILI compared with controls and suggested caution against cloth mask use.

\section{Discussion}

\section{Summary of findings}

In this EM study, concerning mask use for the prevention of the spread of respiratory viruses, we systematically searched for relevant published RCTs and SRs before April 2020. In all, 21 RCTs and nine SRs were included in this study. Among the 21 RCTs, most studies were conducted in China and the USA, and focused on the healthcare workers and household contacts. Overall, masks versus usual practice, 10 of 14 RCTs and 5 of 6 SRs were classified as "beneficial" or "probably beneficial". Furthermore, regarding N95 respirators versus medical masks, 3 of 6 RCTs were classified as "beneficial"; however, $75 \%$ of SRs showed that there was no significant difference between groups. In addition, six RCTs reported adverse effects of wearing masks, with one RCT implying that the cloth mask reuse may increase the risk of infection.

In terms of conclusion ratings, when comparing data between with and without masks, most included RCTs, as well as SRs, showed "beneficial" or "probably beneficial" effects of masks, with a higher number of participants wearing masks grouped in "beneficial" and "probably beneficial" categories compared to any other category $(8,162$ vs. 1,835), thereby suggesting that masks may have a positive effect on interrupting or reducing the spread of respiratory viruses, especially for healthcare workers, all relevant studies included show "probably beneficial" effects of masks. However, when comparing the outcomes with $\mathrm{N} 95$ respirators and those with medical masks, over $70 \%$ of SRs showed "no effect," whereas $50 \%$ of RCTs showed "beneficial" effects. Therefore, we were unable to draw a definitive conclusion on whether the N95 respirator is a better or worse choice than medical masks based on the current evidence. Thus, more relevant high-quality studies are needed for making this conclusion. In addition, among the 10 studies included, the subjects of nine studies were healthcare workers. Combined, the results of these studies largely showed that there were conflicting results regarding whether healthcare workers should wear N95 respirators or medical masks. Moreover, the reasons for this inconformity may be as follows. First, we ascertained the rating of conclusions ("beneficial", "probably beneficial", "harmful", "no effect" and "inconclusive") based on the descriptions of both the results and conclusions of the study; the conclusions of most RCTs considered the study design, intervention compliance, and sample size. Thus, the conclusions may be inconsistent with the statistical results. However, the conclusions of SRs depended more on the statistical effect (56-60). Second, the sample sizes of RCTs categorized into "beneficial" or "probably beneficial" categories and those of RCTs categorized into the "no effect" category were similar (4,551 vs. 3,263) (60).

Regarding the adverse effects of wearing masks, many experts and studies have indicated that given that complete elimination of COVID-19 does not seem likely in the near future, protective measures, such as maintaining social distancing and wearing masks may be necessary for a prolonged time. Furthermore, according to searched studies, insufficient high-quality design research was available that reported on the adverse effects of prolonged mask use. Among the 21 included RCTs, six reported possible adverse effects of prolonged mask use, such as headaches, skin irritation, and respiratory difficulties. In particular, one RCT implied that cloth mask reuse may increase the risk of an infection (61). It is noteworthy that cloth masks are commonly used in developing countries, 
although many non-standard practices around cleaning and cloth mask reuse have evolved. Furthermore, given the COVID-19 situation, many developed countries are widely using cloth masks $(44,62)$. This should draw the attention of the researchers and decision makers. Moreover, there is a lack of RCTs that systematically evaluate the adverse effects of the prolonged wear of masks. This may be because historically, the need to study this has been limited, given that very few pandemics requiring the mask use have been reported. Accordingly, there is limited literature on prolonged mask use, making it difficult to implement RCTs (63-66). A non-RCT reported that masks, especially N95 respirators, affected air intake, thereby decreasing the respiratory efficiency and increasing the respiratory burden (61), and this may affect normal life and even be life threatening for vulnerable populations, such as children, pregnant women, the elderly population, and individuals with chronic diseases or those performing highintensity exercise. Thus, related RCTs should focus on developing a high-quality study design for evaluating this. In addition, for individuals with poor hearing or those who rely on lip reading, whether masks will significantly affect work efficiency and daily communication is worth further research.

The conclusion of this mapping study should be interpreted with caution because of the quality of the included studies. Combined, the quality of the included RCTs was relatively low as only four (4/21, 19.05\%) were assessed to have a "low risk of bias". Furthermore, allocation concealment and outcome assessment blinding were weak links in the design and reporting of the included RCTs, which may affect the authenticity of the reported observations. Moreover, three SRs (3/9, 33.33\%) assessed were of "critically low quality". Particularly, only one SR included "list of excluded studies and justification for exclusion", which needs the attention of researchers in the future.

\section{Evidence gaps and future directions}

Current evidence of high-quality design research concerning the mask use may be insufficient to deal with a second impact of such a pandemic in the future. First, in our study, EM showed that most studies focused on the effectiveness of masks compared with usual practice than that of N95 respirators compared with medical masks. Accordingly, further research is required for differential ratings of conclusions between SRs and RCTs in terms of effectiveness of N95 respirators compared with medical masks, especially for healthcare workers. Second, over $70 \%$ of RCTs focused on healthcare workers and household contacts, and the study of populations in places of gathering, such as students and company staff, was limited. Third, high-quality studies evaluating the adverse events of the prolonged wear of masks are of utmost importance, especially in special populations (such as children, pregnant women, the elderly population, and individuals with chronic diseases, poor hearing, patients who rely on lip reading, or those performing high-intensity exercise), and cases of special reactions (such as the obstruction of vision, skin allergy and sudden death). Fourth, given difficulty in accessing medical masks for many individuals during the pandemic, cloth masks were used as a substitute. However, there is currently only one RCT evaluating the effects of using a cloth mask, which reported that the cloth mask reuse showed a "harmful effect" and may increase the risk of an infection. Accordingly, additional high-quality studies are needed in the future. Fifth, optimal settings and exposure circumstances for populations to use masks should be investigated. For example, high-quality research is needed to explore the effects of wearing masks outdoors as well as indoors.

\section{Strengths and limitations}

Compared with other studies $(9,11)$, our research systematically searched and included relevant high-quality study designs (RCTs and SRs), and used bubble charts to visually present the existing research from multiple important dimensions. Moreover, we ascertained the rating of conclusions based on the descriptions of both the results and conclusions of the studies, which may avoid the uncertainty caused by policy recommendations determined based on only the result or conclusion of studies in a sense $(56,58,63)$. In addition, we found evidence gaps, which not only are instructive for future research and for avoiding the wastage of academic resources but are also of great significance to policy makers. Some limitations of this study should be mentioned. First, we did not include other study designs (such as cohort studies, and case analysis); however, RCTs and SRs usually provide the highest quality evidence for decision-making. Second, our findings are only based on publications before the search date (April 9, 2020). With the emergence of newly related studies, regular updates of the existing results will be done in two years. Third, we did not perform sensitivity analysis, heterogeneity analysis, etc., 
because unlike SRs, these are not performed in EMs.

\section{Conclusions}

The current evidence of high-quality design research concerning mask use may be insufficient to deal with a second impact of such a pandemic in the future. Overall, masks may be effective in interrupting or reducing the spread of respiratory viruses. However, the study conclusions on the effectiveness of N95 respirators over medical masks are contradictory, especially for healthcare workers, and high-quality design evidence for mask use by a special population (such as students and company employees) is rare, and this requires further research. In addition, it is noteworthy that a few adverse effects of wearing masks have been systematically reported in existing high-quality design evidence. Accordingly, many highquality studies are of utmost importance to assess the impact of the prolonged wear of masks on vulnerable populations and to assess the possible adverse events. Finally, in view of the current research, cloth mask reuse may aggravate the spread of respiratory infection, which needs to be further evaluated.

\section{Acknowledgments}

Funding: This study was supported by the Major Project of the National Social Science Fund of China: "Research on the Theoretical System, International Experience and Chinese Path of Evidence-based Social Science" (Project No. 19ZDA142).

\section{Footnote}

Reporting Checklist: The authors have completed the PRISMA reporting checklist. Available at http://dx.doi. org/10.21037/atm-20-6745

Peer Review File: Available at http://dx.doi.org/10.21037/ atm-20-6745

Conflicts of Interest: All authors have completed the ICMJE uniform disclosure form (available at http://dx.doi. org/10.21037/atm-20-6745). The authors have no conflicts of interest to declare.

Ethical statement: The authors are accountable for all aspects of the work in ensuring that questions related to the accuracy or integrity of any part of the work are appropriately investigated and resolved.

Open Access Statement: This is an Open Access article distributed in accordance with the Creative Commons Attribution-NonCommercial-NoDerivs 4.0 International License (CC BY-NC-ND 4.0), which permits the noncommercial replication and distribution of the article with the strict proviso that no changes or edits are made and the original work is properly cited (including links to both the formal publication through the relevant DOI and the license). See: https://creativecommons.org/licenses/by-nc-nd/4.0/.

\section{References}

1. Organization WH. Available online: https://www.who. int/dg/speeches/detail/who-director-general-s-openingremarks-at-the-media-briefing-on-covid-19---11march-2020. 2020.

2. Zhang X, Tan R, Lam WC, et al. PRISMA (Preferred Reporting Items for Systematic Reviews and Meta-Analyses) Extension for Chinese Herbal Medicines 2020 (PRISMACHM 2020). Am J Chin Med 2020;48:1279-313.

3. Adhikari SP, Meng S, Wu YJ, et al. Epidemiology, causes, clinical manifestation and diagnosis, prevention and control of coronavirus disease (COVID-19) during the early outbreak period: a scoping review. Infect Dis Poverty 2020;9:29.

4. Cascella M, Rajnik M, Cuomo A, et al. Features, evaluation and treatment coronavirus (COVID-19). Statpearls [internet]. StatPearls Publishing; 2020.

5. Organization $\mathrm{WH}$. Considerations for quarantine of individuals in the context of containment for coronavirus disease (COVID-19): interim guidance, 29 February 2020: World Health Organization 2020.

6. Organization WH. Management of ill travellers at points of entry-international airports, seaports and ground crossings-in the context of COVID-19 outbreak: interim guidance, 16 February 2020: World Health Organization 2020.

7. Organization $W H$. Rational use of personal protective equipment (PPE) for coronavirus disease (COVID-19): interim guidance, 19 March 2020: World Health Organization 2020.

8. Suess T, Remschmidt C, Schink SB, et al. The role of facemasks and hand hygiene in the prevention of influenza transmission in households: results from a cluster randomised trial; Berlin, Germany, 2009-2011. BMC 
Infect Dis 2012;12:26.

9. Xiao J, Shiu EYC, Gao H, et al. Nonpharmaceutical Measures for Pandemic Influenza in Nonhealthcare Settings-Personal Protective and Environmental Measures. Emerg Infect Dis 2020;26:967.

10. Saunders-Hastings P, Crispo JAG, Sikora L, et al. Effectiveness of personal protective measures in reducing pandemic influenza transmission: A systematic review and meta-analysis. Epidemics 2017;20:1-20.

11. MacIntyre CR, Chughtai AA. Facemasks for the prevention of infection in healthcare and community settings. BMJ 2015;350:h694.

12. Tunis SR, Stryer DB, Clancy CM. Practical clinical trials: increasing the value of clinical research for decision making in clinical and health policy. JAMA 2003;290:1624-32.

13. Glasziou PP, Sanders S, Hoffmann T. Waste in covid-19 research. BMJ 2020;369:m1847.

14. Feng S, Shen C, Xia N, et al. Rational use of face masks in the COVID-19 pandemic. Lancet Respir Med 2020;8:434-6.

15. Anaya MM, Franco JVA, Ballesteros M, et al. Evidence mapping and quality assessment of systematic reviews on therapeutic interventions for oral cancer. Cancer Manag Res 2018;11:117-30.

16. Hetrick SE, Parker AG, Callahan P, et al. Evidence mapping: illustrating an emerging methodology to improve evidence-based practice in youth mental health. J Eval Clin Pract 2010;16:1025-30.

17. Li Y, Li X, Li R, et al. Generation and reporting of evidence mapping. Chinese Journal of Evidence-Based Medicine 2020;20:1098-103.

18. Gaarder M, Snilstveit B, Vojtkova M, et al. Evidence Gap Maps: A Tool for Promoting Evidence-Informed Policy and Prioritizing Future Research. 2013.

19. Sawicki CM, Livingston KA, Ross AB, et al. Evaluating Whole Grain Intervention Study Designs and Reporting Practices Using Evidence Mapping Methodology. Nutrients 2018;10:1052.

20. Singh K, Ansari M, Galipeau J, et al. An Evidence Map of Systematic Reviews to Inform Interventions in Prediabetes. Canadian Journal of Diabetes 2012;36:281-91.

21. Higgins JP, Altman DG, Gøtzsche PC, et al. The Cochrane Collaboration's tool for assessing risk of bias in randomised trials. Bmj 2011;343:d5928.

22. Shea BJ, Reeves BC, Wells G, et al. AMSTAR 2: a critical appraisal tool for systematic reviews that include randomised or non-randomised studies of healthcare interventions, or both. BMJ 2017;358:j4008.

23. Bragge P, Clavisi O, Turner T, et al. The global evidence mapping initiative: scoping research in broad topic areas. BMC Med Res Methodol 2011;11:92.

24. Welch V, Howe T, Marcus S, et al. PROTOCOL: Health, social care and technological interventions to improve functional ability of older adults: Evidence and gap map. Campbell Systematic Reviews 2019;15.

25. Yang K. Evidence-based social science: the origin, development and prospects. Library and Information 2018:1-10.

26. Yang K, Li X, Bai Z. Research methods of Evidencebased social science: Systematic review and meta-analysis. Lanzhou: Lanzhou University Press; 2018.

27. Ballesteros M, Montero N, Lopez-Pousa A, et al. Evidence mapping based on systematic reviews of therapeutic interventions for gastrointestinal stromal tumors (GIST). BMC Med Res Methodol 2017;17:135.

28. Miake-Lye IM, Mak S, Lee J, et al. Massage for Pain: An Evidence Map. J Altern Complement Med 2019;25:475-502.

29. Aiello AE, Murray GF, Perez V, et al. Mask use, hand hygiene, and seasonal influenza-like illness among young adults: a randomized intervention trial. J Infect Dis 2010;201:491-8.

30. Aiello AE, Perez V, Coulborn RM, et al. Facemasks, hand hygiene, and influenza among young adults: a randomized intervention trial. PLoS One 2012;7:e29744.

31. Atrie D, Worster A. Surgical mask versus N95 respirator for preventing influenza among health care workers: a randomized trial. CJEM 2012;14:50-2.

32. Barasheed O, Almasri N, Badahdah AM, et al. Pilot Randomised Controlled Trial to Test Effectiveness of Facemasks in Preventing Influenza-like Illness Transmission among Australian Hajj Pilgrims in 2011. Infect Disord Drug Targets 2014;14:110-6.

33. Canini L, Andreoletti L, Ferrari P, et al. Surgical mask to prevent influenza transmission in households: a cluster randomized trial. PLoS One 2010;5:e13998.

34. Cowling BJ, Fung RO, Cheng CK, et al. Preliminary findings of a randomized trial of non-pharmaceutical interventions to prevent influenza transmission in households. PLoS One 2008;3:e2101.

35. Cowling BJ, Chan KH, Fang VJ, et al. Facemasks and hand hygiene to prevent influenza transmission in households: A cluster randomized trial. Ann Intern Med 2009; 151:437-46.

36. Jacobs JL, Ohde S, Takahashi O, et al. Use of surgical face 
masks to reduce the incidence of the common cold among health care workers in Japan: a randomized controlled trial. Am J Infect Control 2009;37:417-9.

37. Larson EL, Ferng YH, Wong-McLoughlin J, et al. Impact of non-pharmaceutical interventions on URIs and influenza in crowded, urban households. Public Health Rep 2010;125:178-91.

38. Leung NHL, Chu DKW, Shiu EYC, et al. Respiratory virus shedding in exhaled breath and efficacy of face masks. Nat Med 2020;26:676-80.

39. Loeb M, Dafoe N, Mahony J, et al. Surgical mask vs N95 respirator for preventing influenza among health care workers: a randomized trial. JAMA 2009;302:1865-71.

40. MacIntyre CR, Cauchemez S, Dwyer DE, et al. Face mask use and control of respiratory virus transmission in households. Emerg Infect Dis 2009;15:233-41.

41. MacIntyre CR, Wang Q, Cauchemez S, et al. A cluster randomized clinical trial comparing fit-tested and nonfit-tested N95 respirators to medical masks to prevent respiratory virus infection in health care workers. Influenza Other Respir Viruses 2011;5:170-9.

42. MacIntyre CR, Wang Q, Seale H, et al. A randomized clinical trial of three options for N95 respirators and medical masks in health workers. Am J Respir Crit Care Med 2013;187:960-6.

43. MacIntyre CR, Wang Q, Rahman B, et al. Efficacy of face masks and respirators in preventing upper respiratory tract bacterial colonization and co-infection in hospital healthcare workers. Prev Med 2014;62:1-7.

44. MacIntyre CR, Seale H, Dung TC, et al. A cluster randomised trial of cloth masks compared with medical masks in healthcare workers. BMJ Open 2015;5:e006577.

45. MacIntyre CR, Zhang Y, Chughtai AA, et al. Cluster randomised controlled trial to examine medical mask use as source control for people with respiratory illness. BMJ Open 2016;6:e012330.

46. Radonovich LJ, Jr., Simberkoff MS, Bessesen MT, et al. N95 Respirators vs Medical Masks for Preventing Influenza Among Health Care Personnel: A Randomized Clinical Trial. JAMA 2019;322:824-33.

47. Simmerman JM, Suntarattiwong P, Levy J, et al. Findings from a household randomized controlled trial of hand washing and face masks to reduce influenza transmission in Bangkok, Thailand. Influenza Other Respir Viruses 2011;5:256-67.

48. Thomas F, Allen C, Butts W, et al. Does wearing a surgical facemask or N95-respirator impair radio communication? Air Med J 2011;30:97-102.
49. Bartoszko JJ, Farooqi MAM, Alhazzani W, et al. Medical Masks vs N95 Respirators for Preventing COVID-19 in Health Care Workers A Systematic Review and MetaAnalysis of Randomized Trials. Influenza Other Respir Viruses 2020;14:365-73.

50. Bin-Reza F, Lopez Chavarrias V, Nicoll A, et al. The use of masks and respirators to prevent transmission of influenza: A systematic review of the scientific evidence. Influenza Other Respir Viruses 2012;6:257-67.

51. Jefferson T, Del Mar CB, Dooley L, et al. Physical interventions to interrupt or reduce the spread of respiratory viruses. Cochrane Database Syst Rev 2011;2011:CD006207.

52. Long $\mathrm{Y}, \mathrm{Hu}$ T, Liu L, et al. Effectiveness of N95 respirators versus surgical masks against influenza: A systematic review and meta-analysis. J Evid Based Med 2020;13:93-101.

53. Offeddu V, Yung CF, Low MSF, et al. Effectiveness of Masks and Respirators Against Respiratory Infections in Healthcare Workers: A Systematic Review and MetaAnalysis. Clin Infect Dis 2017;65:1934-42.

54. Smith JD, MacDougall CC, Johnstone J, et al. Effectiveness of $\mathrm{N} 95$ respirators versus surgical masks in protecting health care workers from acute respiratory infection: A systematic review and meta-analysis. CMAJ 2016;188:567-74.

55. Wong VWY, Cowling BJ, Aiello AE. Hand hygiene and risk of influenza virus infections in the community: A systematic review and meta-analysis. Epidemiol Infect 2014;142:922-32.

56. Ge L, Tian J-h, Li Y-n, et al. Association between prospective registration and overall reporting and methodological quality of systematic reviews: a metaepidemiological study. J Clin Epidemiol 2018;93:45-55.

57. Tian J, Zhang J, Ge L, et al. The methodological and reporting quality of systematic reviews from China and the USA are similar. J Clin Epidemiol 2017;85:50-8.

58. Xiu-xia L, Ya Z, Yao-long C, et al. The reporting characteristics and methodological quality of Cochrane reviews about health policy research. Health Policy 2015;119:503-10.

59. Yao L, Sun R, Chen Y-L, et al. The quality of evidence in Chinese meta-analyses needs to be improved. J Clin Epidemiol 2016;74:73-9.

60. Delgado-Rodríguez M, Sillero-Arenas M. Systematic review and meta-analysis. Med Intensiva 2018;42:444-53.

61. Tong PSY, Kale AS, Ng K, et al. Respiratory consequences of N95-type Mask usage in pregnant healthcare workers-a 


\section{Page 16 of 16}

controlled clinical study. Antimicrobial Resistance and Infection Control 2015;4:48.

62. CDC T. Available online: https://www.cdc.gov/ coronavirus/2019-ncov/prevent-getting-sick/diy-clothface-coverings.html. 2020.

63. Bhargava A. Randomized controlled experiments in health and social sciences: some conceptual issues. Econ Hum Biol 2008;6:293-8.

Cite this article as: $\mathrm{Li} \mathrm{Y,} \mathrm{Wei} \mathrm{Z,} \mathrm{Zhang} \mathrm{J,} \mathrm{Li} \mathrm{R,} \mathrm{Li} \mathrm{H,} \mathrm{Cao} \mathrm{L,}$ Hou L, Zhang W, Chen N, Guo K, Li X, Yang K. Wearing masks to reduce the spread of respiratory viruses: a systematic evidence mapping. Ann Transl Med 2021;9(9):811. doi: 10.21037/atm-20-6745

\section{Li et al. Wearing masks to reduce the spread of respiratory viruses}

64. Lina B. History of Influenza Pandemics. 2008. p. 199-211.

65. Mossad SB. Influenza update 2018-2019: 100 years after the great pandemic. Cleveland Clinic Journal of Medicine 2018;85:861-9.

66. Qin Y, Zhao M, Tan Y, et al. History of influenza pandemics in China during the past century. Zhonghua liu xing bing xue za zhi 2018;39:1028-31. 


\section{Contents}

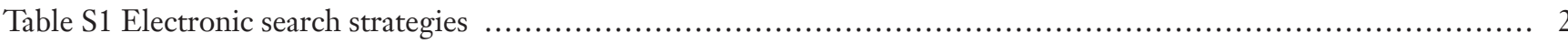

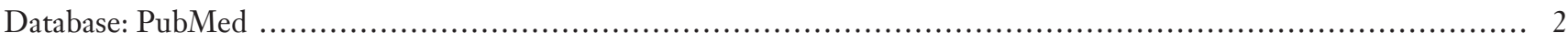

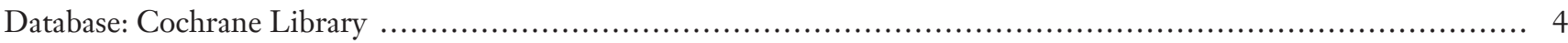

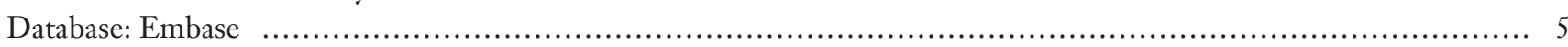

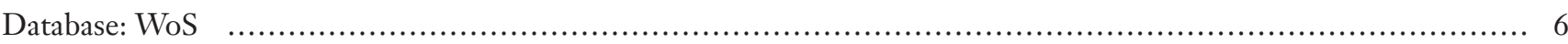

Database: WHO International Clinical Trials Registry Platform (ICTRP) Search Portal ............................ 6

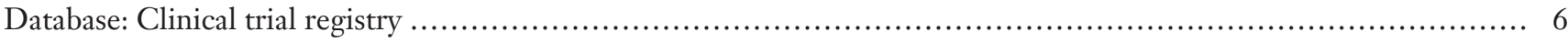

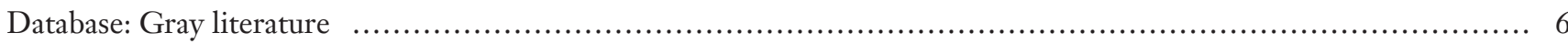

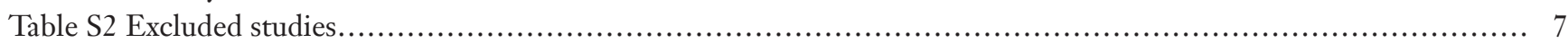

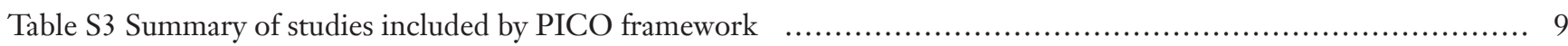

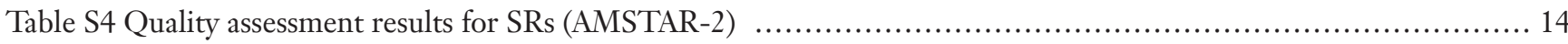

Table S1 Electronic search strategies

\begin{tabular}{lc}
\hline Databases [Platform] Searches run April 2020 & Results \\
\hline PubMed & 1253 \\
Cochrane Library & 517 \\
Embase & 1781 \\
WOS & 2611 \\
Other sources (ClinicalTrials.gov, gray literature, and reference lists of articles) & 844 \\
TOTAL & 7006 \\
Duplicate & 1512
\end{tabular}

Database: PubMed <April 9th 2020> 1253

Search Strategy:

\begin{tabular}{|c|c|c|}
\hline$\#$ & Searches & Results \\
\hline$\# 1$ & "Masks"[Mesh] & 9270 \\
\hline \#2 & $\begin{array}{l}\text { Search Terms: (mask OR facemask OR FFP2 OR respirators OR masks OR N95 OR respirator OR "personal } \\
\text { protection equipment" OR "personal protective equipment" OR protective devices OR respiratory protective } \\
\text { devices) } \\
\text { Search Fields: Title/Abstract }\end{array}$ & 43723 \\
\hline$\# 3$ & \#1 OR \#2 & 46102 \\
\hline & $\begin{array}{l}\text { Search Terms: ("particulate matter" OR respiratory OR ARI OR chickenpox OR CRI OR droplet OR particle } \\
\text { OR pathogen OR epidemic OR flu OR H1N1 OR coronavirus OR haemophilus OR aerosol OR "health care } \\
\text { acquired" OR "health care associated" OR "healthcare acquired" OR "healthcare associated" OR "chicken } \\
\text { pox" OR "hospital acquired" OR adenovirus OR "hospital associated" OR communicable OR HiB OR ILI OR } \\
\text { bioaerosol OR infect OR cross infect OR influenza OR airborne OR measles OR MERS OR metapneumovirus }\end{array}$ & \\
\hline \#4 & $\begin{array}{l}\text { OR bacteri OR "Middle East respiratory syndrome" OR pandemic OR orthomyxoviridae OR parainfluenza } \\
\text { OR particle OR paramyxoviridae OR pathogen OR "respiratory disease" OR pneumonia OR "respiratory } \\
\text { illness" OR "respiratory hygiene" OR "respiratory tract" OR "respiratory infection" OR rhinovirus OR virus OR } \\
\text { "respiratory virus" OR RSV OR SARS-CoV-2 OR COVID-19 OR SARS OR virion OR "severe acute respiratory } \\
\text { syndrome" OR viral OR pertussis OR varicella OR "whooping cough") } \\
\text { Search Fields: Title/Abstract }\end{array}$ & 1859227 \\
\hline \#5 & "Respiratory Tract Infections"[Mesh] & 353327 \\
\hline \#6 & \#4 OR \#5 & 2047316 \\
\hline & $\begin{array}{l}\text { "Clinical Trials, Phase II as Topic"[Mesh] OR "Clinical Trials, Phase III as Topic"[Mesh] OR "Clinical Trials, } \\
\text { Phase IV as Topic"[Mesh] OR "Controlled Clinical Trials as Topic"[Mesh] OR "Randomized Controlled Trials } \\
\text { as Topic"[Mesh] OR "Intention to Treat Analysis"[Mesh] OR "Pragmatic Clinical Trials as Topic"[Mesh] OR }\end{array}$ & \\
\hline$\# 7$ & $\begin{array}{l}\text { "Clinical Trials, Phase II"[Publication Type] OR "Clinical Trials, Phase III”[Publication Type] OR "Clinical Trials, } \\
\text { Phase IV"[Publication Type] OR “Controlled Clinical Trials"[Publication Type] OR "Randomized Controlled } \\
\text { Trials"[Publication Type] OR "Pragmatic Clinical Trials as Topic"[Publication Type] OR "Single-Blind } \\
\text { Method"[Mesh] OR "Double-Blind Method"[Mesh] }\end{array}$ & 325776 \\
\hline \#8 & $\begin{array}{l}\text { Search Terms: (random* OR singleblind }{ }^{*} \text { OR blind }{ }^{*} \text { OR doubleblind }{ }^{*} \text { OR tripleblind* OR trebleblind }{ }^{*} \text { ) } \\
\text { Search Fields: Title/Abstract }\end{array}$ & 1255768 \\
\hline \#9 & \#7 OR \#8 & 1352738 \\
\hline$\# 10$ & \#3 AND \#6 AND \#9 & 1253 \\
\hline
\end{tabular}


Database: Cochrane Library <April 9th 2020> 517

Search Strategy:

\begin{tabular}{|c|c|c|}
\hline$\#$ & Searches & Results \\
\hline$\# 1$ & [Masks] explode all trees & 1513 \\
\hline \#2 & $\begin{array}{l}\text { (mask or facemask or FFP2 or respirators or masks or N95 or respirator or "personal protection equipment" } \\
\text { or "personal protective equipment" or protective devices or respiratory protective devices):ti }\end{array}$ & 4941 \\
\hline$\# 3$ & \#1 OR \#2 & 5396 \\
\hline$\# 4$ & [Respiratory Tract Infections] explode all trees & 14230 \\
\hline \#5 & $\begin{array}{l}\text { ("particulate matter" or respiratory or ARI or chickenpox or CRI or droplet or particle or pathogen or } \\
\text { epidemic or flu or H1N1 or coronavirus or haemophilus or aerosol or "health care acquired" or "health care } \\
\text { associated" or "healthcare acquired" or "healthcare associated" or "chicken pox" or "hospital acquired" } \\
\text { or adenovirus or "hospital associated" or communicable or HiB or ILI or bioaerosol or infect or cross infect } \\
\text { or influenza or airborne or measles or MERS or metapneumovirus or bacteri or "Middle East respiratory } \\
\text { syndrome" or pandemic or orthomyxoviridae or parainfluenza or particle or paramyxoviridae or pathogen } \\
\text { or "respiratory disease" or pneumonia or "respiratory illness" or "respiratory hygiene" or "respiratory tract" } \\
\text { or "respiratory infection" or rhinovirus or virus or "respiratory virus" or RSV or SARS-CoV-2 or COVID-19 } \\
\text { or SARS or virion or "severe acute respiratory syndrome" or viral or pertussis or varicella or "whooping } \\
\text { cough"):ti }\end{array}$ & 63755 \\
\hline \#6 & \#4 OR \#5 & 71118 \\
\hline$\# 7$ & \#3 AND \#6 & 517 \\
\hline
\end{tabular}

Database: Embase <April 9th 2020> 1781

Search Strategy:

\begin{tabular}{|c|c|c|}
\hline \# & Searches & Results \\
\hline$\# 1$ & 'mask'/exp & 34117 \\
\hline \#2 & $\begin{array}{l}\text { Search Terms: (mask OR facemask OR FFP2 OR respirators OR masks OR N95 OR respirator OR "personal } \\
\text { protection equipment" OR "personal protective equipment" OR protective devices OR respiratory protective } \\
\text { devices) } \\
\text { Search Fields: Title/Abstract }\end{array}$ & 55540 \\
\hline$\# 3$ & \#1 OR \#2 & 75059 \\
\hline$\# 4$ & 'respiratory tract infection'/exp & 453102 \\
\hline$\# 5$ & $\begin{array}{l}\text { Search Terms: ("particulate matter" OR respiratory OR ARI OR chickenpox OR CRI OR droplet OR particle } \\
\text { OR pathogen OR epidemic OR flu OR H1N1 OR coronavirus OR haemophilus OR aerosol OR "health } \\
\text { care acquired" OR "health care associated" OR "healthcare acquired" OR "healthcare associated" OR } \\
\text { "chicken pox" OR "hospital acquired" OR adenovirus OR "hospital associated" OR communicable OR } \\
\text { HiB OR ILI OR bioaerosol OR infect OR cross infect OR influenza OR airborne OR measles OR MERS OR } \\
\text { metapneumovirus OR bacteri OR "Middle East respiratory syndrome" OR pandemic OR orthomyxoviridae } \\
\text { OR parainfluenza OR particle OR paramyxoviridae OR pathogen OR "respiratory disease" OR pneumonia } \\
\text { OR "respiratory illness" OR "respiratory hygiene" OR "respiratory tract" OR "respiratory infection" OR } \\
\text { rhinovirus OR virus OR "respiratory virus" OR RSV OR SARS-CoV-2 OR COVID-19 OR SARS OR virion OR } \\
\text { "severe acute respiratory syndrome" OR viral OR pertussis OR varicella OR "whooping cough") } \\
\text { Search Fields: Title/Abstract }\end{array}$ & 2283350 \\
\hline$\# 6$ & \#4 OR \#5 & 2507169 \\
\hline$\# 7$ & $\begin{array}{l}\text { 'phase } 2 \text { clinical trial (topic)'/exp OR 'multicenter study (topic)'/exp OR 'phase } 3 \text { clinical trial (topic)'/exp } \\
\text { OR 'controlled clinical trial (topic)'/exp OR 'phase } 4 \text { clinical trial (topic)'/exp OR 'randomized controlled trial } \\
\text { (topic)'/exp OR 'double blind procedure'/exp' OR single blind procedure'/exp }\end{array}$ & 427430 \\
\hline \#8 & $\begin{array}{l}\text { Search Terms: (random OR singleblind* OR blind* OR doubleblind* OR tripleblind* OR trebleblind*) } \\
\text { Search Fields: Title/Abstract }\end{array}$ & 1707345 \\
\hline$\# 9$ & \#7 OR \#8 & 1865091 \\
\hline$\# 10$ & \#3 AND \#6 AND \#9 & 1781 \\
\hline
\end{tabular}


Database: $W o S<A$ pril 9 th $2020>2611$

Search Strategy:

\begin{tabular}{ll}
\hline$\# \quad$ Searches \\
\hline \#1 & TOPIC: (mask or facemask or FFP2 or respirators or masks or N95 or respirator or "personal protection \\
& equipment" or "personal protective equipment" or protective devices or respiratory protective devices) \\
& TOPIC: ("particulate matter" or respiratory or ARI or chickenpox or CRI or droplet or particle or pathogen or \\
& epidemic or flu or H1N1 or coronavirus or haemophilus or aerosol or "health care acquired" or "health care \\
& associated" or "healthcare acquired" or "healthcare associated" or "chicken pox" or "hospital acquired" \\
& or adenovirus or "hospital associated" or communicable or HiB or ILI or bioaerosol or infect or cross infect \\
& or influenza or airborne or measles or MERS or metapneumovirus or bacteri or "Middle East respiratory \\
& syndrome" or pandemic or orthomyxoviridae or parainfluenza or particle or paramyxoviridae or pathogen \\
& or "respiratory disease" or pneumonia or "respiratory illness" or "respiratory hygiene" or "respiratory tract" \\
& or "respiratory infection" or rhinovirus or virus or "respiratory virus" or RSV or SARS-CoV-2 or COVID-19 \\
& or SARS or virion or "severe acute respiratory syndrome" or viral or pertussis or varicella or "whooping \\
& cough") \\
TOPIC: (randomized controlled trial OR Clinical trial OR Controlled Clinical trial OR random* OR singleblind* & 3570063 \\
OR blind* OR doubleblind* OR tripleblind* OR trebleblind*) & 2305918 \\
\#3 AND \#2 AND \#1 & 2611 \\
&
\end{tabular}

Database: WHO International Clinical Trials Registry Platform (ICTRP) Search Portal <April 27th 2020>86 Search terms: "mask"; applied filters: "With Results" and "Interventional"

Database: Clinical trial registry <April 27th 2020>351

Search terms: "mask"; applied filters: "With Results" and "Interventional"

Database: Gray literature <April 27th 2020> 402

Search term: "mask": 402 


\begin{tabular}{l}
\hline Title \\
\hline Results of the respiratory protection effectiveness clinical trial (respect) \\
The First Randomized, Controlled Clinical Trial of Mask Use in Households \\
to Prevent Respiratory Virus Transmission \\
A randomized intervention trial of mask use and hand hygiene to reduce \\
seasonal influenza-like illness and influenza infections among young \\
adults in a university setting
\end{tabular}
adults in a university setting

Influence of household contacts on the effectiveness of face masks for preventing influenza in a healthcare setting: a comment on Cowling et al. Health care worker use of N95 respirators vs medical masks did not differ for workplace-acquired influenza

A randomised controlled pilot study to compare filtration factor of a novel non-fit-tested high-efficiency particulate air (HEPA) filtering facemask with a fit-tested N95 mask

Efficacy of face masks and respirators in preventing upper respiratory

tract bacterial colonization and co-infection in hospital healthcare workers - Comment on the article by Macintyre et al

Surgical masks vs $\mathrm{N} 95$ respirators for preventing influenza

The efficacy and safety of laryngeal mask versus endotracheal tubes for laparoscopic surgery: A meta-analysis

Airway Complications during and after General Anesthesia: A Comparison, Systematic Review and Meta-Analysis of Using Flexible Laryngeal Mask Airways and Endotracheal Tubes

Effect of reduction in household air pollution on childhood pneumonia in Guatemala (RESPIRE): a randomised controlled trial

The use of gowns and masks to control respiratory illness in pediatric hospital personnel

Comparison of laryngeal mask airway Supreme and laryngeal mask airway Pro-Seal for controlled ventilation during general anaesthesia in adult patients: Systematic review with meta-analysis

Optimal dose of succinylcholine for laryngeal mask airway insertion: systematic review, meta-analysis and metaregression of randomised control trials

The impact of laryngeal mask versus other airways on perioperative respiratory adverse events in children: A systematic review and metaanalysis of randomized controlled trials

Effect of airway clearance techniques in patients experiencing an acute exacerbation of chronic obstructive pulmonary disease: A systematic review

The effect of sevoflurane versus desflurane on the incidence of upper respiratory morbidity in patients undergoing general anesthesia with a Laryngeal Mask Airway: A meta-analysis of randomized controlled trials A systematic review and meta-analysis of the i-gel((R)) vs laryngeal mask airway in adults

Laryngeal Mask Airway Versus Other Airway Devices for Anesthesia in Children With an Upper Respiratory Tract Infection: A Systematic Review and Meta-analysis of Respiratory Complications

Non-invasive ventilation improves respiratory distress in children with acute viral bronchiolitis: A systematic review

Comparison of the effectiveness of inhaler devices in asthma and chronic obstructive airways disease: a systematic review of the literature

The advantages of the LMA over the tracheal tube or facemask: a metaanalysis

Comparative efficacy and safety of the $\mathrm{Ambu}(\mathrm{R}))$ AuraOnce 0 laryngeal mask airway during general anaesthesia in adults: a systematic review and meta-analysis

Household transmission of influenza A and B in a school-based study of non-pharmaceutical interventions

Protection by Face Masks against Influenza A(H1N1)pdm09 Virus on Trans-Pacific Passenger Aircraft, 2009

Respiratory consequences of N95-type Mask usage in pregnant healthcare workers-a controlled clinical study

Public perceptions of non-pharmaceutical interventions for reducing transmission of respiratory infection: systematic review and synthesis of qualitative studies

Facemasks and intensified hand hygiene in a German household trial during the 2009/2010 influenza A(H1N1) pandemic: adherence and tolerability in children and adults

Who should wear mask against airborne infections? Altering the contact network for controlling the spread of contagious diseases

The efficacy of medical masks and respirators against respiratory infection in healthcare workers

Prevalence of preventive behaviors and associated factors during early phase of the H1N1 influenza epidemic

Impact of the flu mask regulation on health care personnel influenza vaccine acceptance rates

Aerosol transmission is an important mode of influenza A virus spread Facemasks for the prevention of infection in healthcare and community settings
Author, year

Reason for Exclude

Abstract

MacIntyre, C. R, 2018

Abstract

Aiello, A. E, 2010

Abstract

Williams, C. J, 2010

Comment

Glatt, A. E, 2020

Comment

Au, S. S, 2010

Laboratory research

Soerokromo, N. S, 2014

Letters

Clynes, N, 2010

Letters

Yasen, Y, 2017

Wrong intervention

Xu, R, 2016

Wrong intervention

Smith, K. R, 2011

Wrong intervention

Wrong intervention: multiple interventions

Wrong intervention

Maitra, S, 2014

Liao, A. H, 2017

Wrong intervention

Li, L, 2019

Wrong intervention

Hill, K, 2010

Wrong intervention

De Oliveira Jr, G. S, $2013 \quad$ Wrong intervention

de Montblanc, J, $2014 \quad$ Wrong intervention

de Carvalho, A. L. R, 2018 Wrong intervention

Combret, Y, 2017

Wrong intervention

Brocklebank, D.

Ram, F, 2001

Brimacombe, J, 1995

Wrong intervention

Wrong intervention

Baidya, D. K, 2014

Wrong intervention

Azman, A. S, 2013

Wrong intervention

Zhang, L. J, 2013

Wrong research design

Tong, P. S. Y, 2015

Wrong research design: CCT

Teasdale, E, 2014

Wrong research design

Suess, T, 2011

Wrong research design

Schimit, P. H. T, 2010

Wrong research design

MacIntyre, C. R, 2017

Wrong research design

Lau, J. T. F, 2010

Wrong research design

Edwards, F, 2016

Wrong research design

Cowling, B. J, 2013

Wrong research design

Maclntyre, C. R,2015

Wrong research design 


\begin{tabular}{|c|c|c|c|c|c|c|c|}
\hline Study & Country & $\begin{array}{ll}\text { Objectiveness } \\
\end{array}$ & Population and Setting & Experimental & Control & Result & Conclusion \\
\hline Aiello AE,2010 & USA & To examine the role of masks and hand hygiene in preventing IL' & $\begin{array}{l}\text { 1437 students living in university residence halls; } 1297 \\
\text { residents further analyzed }\end{array}$ & $\begin{array}{l}\text { Hand saninizer and medicial masks and } \\
\text { education; medical mask and education }\end{array}$ & Only education nittevention & 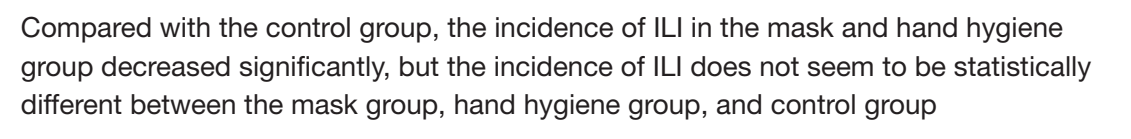 & $\begin{array}{l}\text { Hand hygiene and mask interention may be effective in reducing the } \\
\text { occurrenco of ressiritory diseases and recucing the adverse effects of the } \\
\text { pandemic. }\end{array}$ \\
\hline Aiello AE,2012 & USA & $\begin{array}{l}\text { To explore the effects of using masks and hand hygiene in the } \\
\text { naturual setting to prevent influenza }\end{array}$ & $\begin{array}{l}1178 \text { students living in university residence halls; } 1111 \\
\text { residents further analyzed }\end{array}$ & $\begin{array}{l}\text { Hand sanitizer and medical masks and } \\
\text { education; medical masks and education }\end{array}$ & $\begin{array}{l}\text { Received the same education but no } \\
\text { additional interventions }\end{array}$ & $\begin{array}{l}\text { Compared with the control froup, the incidence of influenzza in the inteventition group } \\
\text { (mask group) did not signnificantly decrease }\end{array}$ & $\begin{array}{l}\text { In the community enviromment the combined use of masks and hand hygiene } \\
\text { can refuce the occurrence of influenza }\end{array}$ \\
\hline Atrie D,2012 & Canada & 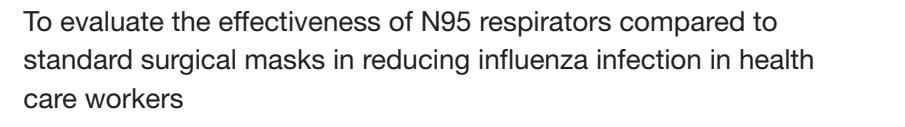 & $446 \mathrm{HCWs}$ recruited from eight hospitals & No5 respirator & surgical mask & 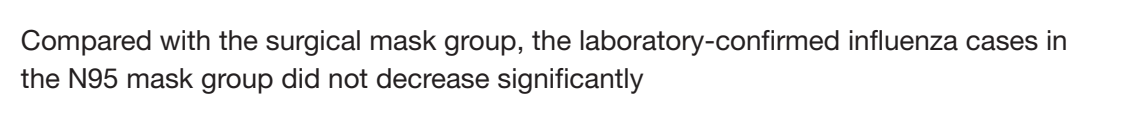 & $\begin{array}{l}\text { The protetition provided by yn N95 respiratoto is not superior to that provided by } \\
\text { a standards surgical mask }\end{array}$ \\
\hline Barasheed 0,2014 & Saudi Arabia & To determine the effectiveness of facemasks in preventing influenza & 164 Australan pilgrims recruited from 2011 Hajj & Surgical mask & No facemasks provided & 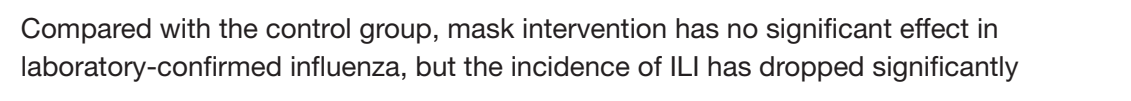 & $\begin{array}{l}\text { This was a pilot study with smal sample, which has shown the feasibility of a } \\
\text { tuture tullscale study }\end{array}$ \\
\hline Canini L,2010 & France & $\begin{array}{l}\text { To evaluate the effectiveness of facemask use for preventing } \\
\text { influenzza in housenholds }\end{array}$ & $\begin{array}{l}\text { 372 housenolds recruited from general practitioner } \\
\text { clinicis; } 10 \text { housenholds which included } 306 \text { household } \\
\text { contacts further analyzed }\end{array}$ & Surgical mask & No facemasks provided & $\begin{array}{l}\text { No significant difiference in preventing transmission of influenza in housenolds between } \\
\text { control and mast--nny y yroup }\end{array}$ & $\begin{array}{l}\text { Due to the lack of corresponding evidence, we cannot draw a definite } \\
\text { conclusion }\end{array}$ \\
\hline Cowling BJ,2008 & China & 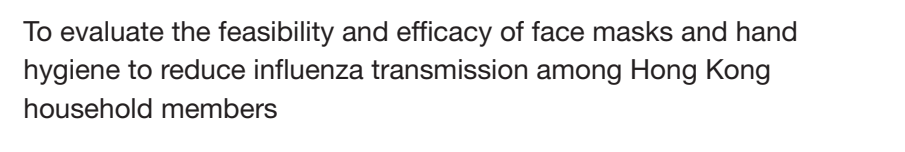 & 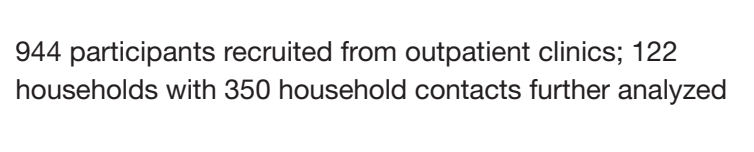 & $\begin{array}{l}\text { Hand sanitizer and education; surgical face } \\
\text { masks and education }\end{array}$ & Heathy diet and lifestyle education & $\begin{array}{l}\text { No significant reduction in the secondary influenzza attack rate in control, mask or hand } \\
\text { group }\end{array}$ & 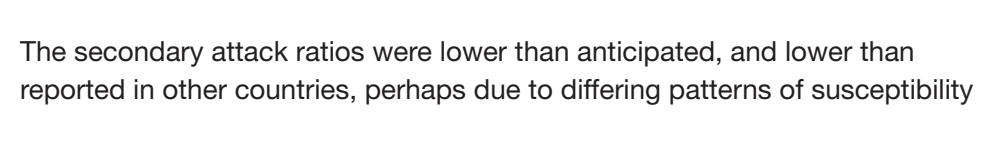 \\
\hline Cowing B,2009 & China & $\begin{array}{l}\text { To investigate whether hand hygiene and use of face-masks } \\
\text { prevents housenold transmission of influenzza }\end{array}$ & 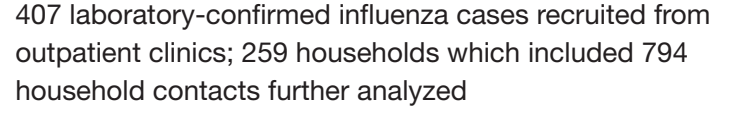 & $\begin{array}{l}\text { Hand hygiene; surgical facemasks plus hand } \\
\text { hygiene }\end{array}$ & Heathy diet and lifestyle education & $\begin{array}{l}\text { No significant difiference in rates of flaboratory-confirmed influenza in control, hand-only } \\
\text { or mask and hand group }\end{array}$ & 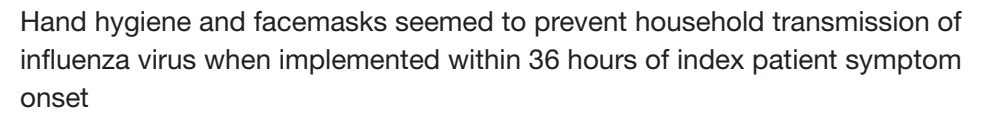 \\
\hline Jacobs JL,2009 & Japan & $\begin{array}{l}\text { To vevaluatet he effectiveness of face masks in reducing influenza } \\
\text { infection in HCWs }\end{array}$ & $32 \mathrm{HCW}$ s recrutited from a tertiary care hospital in Japan & Surgical mask & No facemasks provided & No difference in sell-reported cold symptoms between control and face mask & $\begin{array}{l}\text { For health care workers' cold incidence, the benefits of using masks haven not } \\
\text { been proven }\end{array}$ \\
\hline Larson EL,2010 & USA & 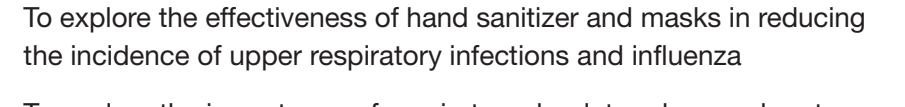 & 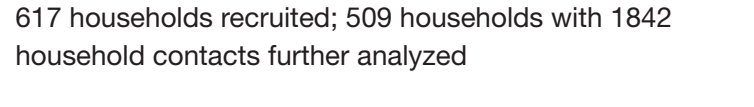 & $\begin{array}{l}\text { Hand sanitizer and surgica mask and } \\
\text { education; hand sanitizer and education }\end{array}$ & Education & $\begin{array}{l}\text { Nos significant reduction in rates of f aboratary-confirmed influenza in control, hand--only, } \\
\text { mask or hand group }\end{array}$ & Wearing a mask seems to reduce the spread of influenza \\
\hline Leung NHL,2020 & China & 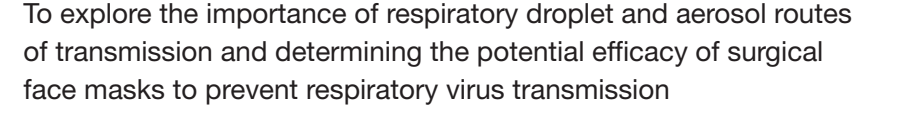 & $\begin{array}{l}244 \text { exposedd participants recrutited from a general } \\
\text { outpatient clinic of pa private hospital in Hong Kong, China }\end{array}$ & Surgical face masks & No facemasks provided & 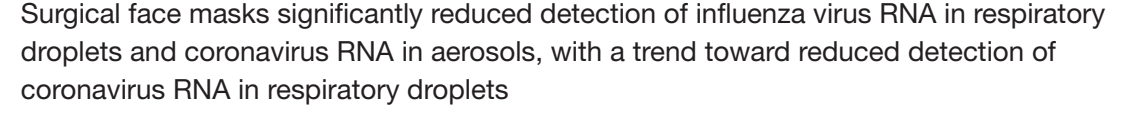 & $\begin{array}{l}\text { Surgical face masks could prevenet transmission } \\
\text { influenza viruses from symptomatic individuals }\end{array}$ \\
\hline Loeb M,2009 & Canada & $\begin{array}{l}\text { To compare the surgical mask with the N95 respirator in protecting } \\
\text { HCWs aganist influenza }\end{array}$ & 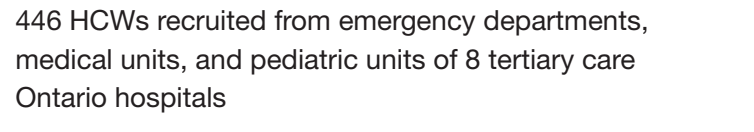 & -tested N95 respriatator & Surgical mask & 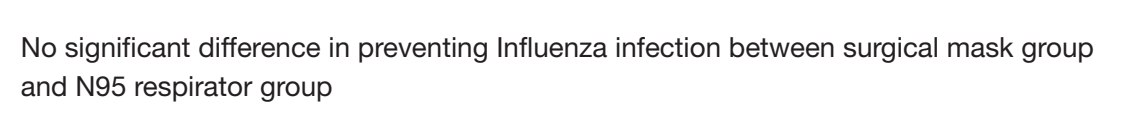 & 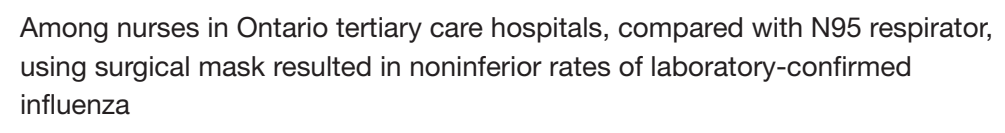 \\
\hline Machntyre CR,2009 & Australia & $\begin{array}{l}\text { To comparat the efficicacy of surgicial masks, non-fittetested P2 masks, } \\
\text { and no masks in prevention of LL in households }\end{array}$ & $\begin{array}{l}286 \text { exposed participants from } 143 \text { housenolds recruted } \\
\text { trom a pediatric heath service }\end{array}$ & Surgical mask; P2 mask & No facemasks provided & $\begin{array}{l}\text { No significant difference in rate of laboratory confirmed influenzza in control, face mask- } \\
\text { only or P2 mask-only group }\end{array}$ & $\begin{array}{l}\text { Face masks si ineffictive for controlling seasonal respiratory yiseasese However, } \\
\text { the use of masks may block the spread of the virus during severe epidemic }\end{array}$ \\
\hline Maclintyre CR,2011 & China & 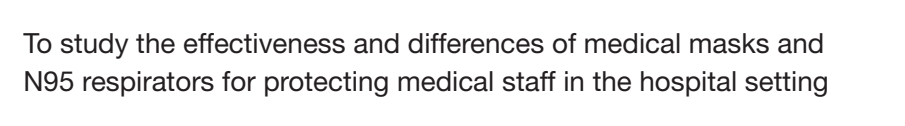 & 1441 HCWS recruted from 15 Beijing hospitals & $\begin{array}{l}\text { Fit-tested N95 respirator; non-Fit-tested } \\
\text { N95 respiriator }\end{array}$ & Medical masks & $\begin{array}{l}\text { Compared with the N95 respiratar r group, the incidence of infrection in the medical mask } \\
\text { group was higher }\end{array}$ & N95 ressirators seem to be more effective than medical $\mathrm{m}$ \\
\hline Maclintyre CR,2013 & China & 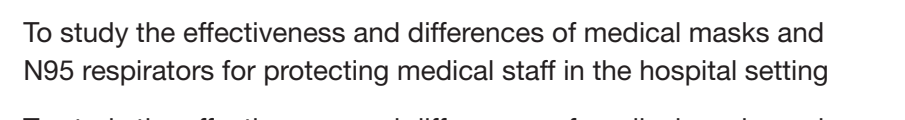 & 1069 HCWS recruted from 19 Beifing hospitals & $\begin{array}{l}\text { No5 ressinitars: tarageted use of N95 } \\
\text { respiratores }\end{array}$ & Medical masks & $\begin{array}{l}\text { Compared with the medical mask group, the incidence of CRl is lower in the N95 } \\
\text { respiritars }\end{array}$ & $\begin{array}{l}\text { No5 respirators are more effective than medical masks for the prevention of } \\
\text { CRl, spsecilly continuous use of them }\end{array}$ \\
\hline Macintyre CR,2014 & China & $\begin{array}{l}\text { To study the effectiveness and differences of medical masks and } \\
\text { N95 respiritors tor protecting medical staffin the hospital setting }\end{array}$ & 1441 HCWs recruited from 15 Beejing hospitals & N95 respiriator & Medical masks & N95 respirators were significantly protective against bacterial colonization. & $\begin{array}{l}\text { No5 masks have a significant effect on preventing infections of healthcare } \\
\text { workers }\end{array}$ \\
\hline Maclintyre CR,2015 & Vietnam & $\begin{array}{l}\text { To study the effectiveness and differences of medical masks and } \\
\text { cloth masks sor protecting medical staffi in the hossital setting }\end{array}$ & 1607 HCWs recruited from 14 hospitals & Medical mask; cloth masks & Usual practice & $\begin{array}{l}\text { Compared with the medical mask group, the infection rate in the eloth mask group was } \\
\text { significanty higher }\end{array}$ & $\begin{array}{l}\text { The cloth mask group has a higher infection rate and should be used with } \\
\text { caution }\end{array}$ \\
\hline Machntyre CR,2016 & China & To study the effectiveness of medical masks in preventing infections & $\begin{array}{l}244 \mathrm{I} \text { c casses and } 5977 \text { household contacts recruted } \\
\text { from fever clinics }\end{array}$ & Medical mask & No facemasks provided & $\begin{array}{l}\text { Cilicical respiratotoy ylliness, IL and laboratory-confirmed viral infections were lower in } \\
\text { the mask-only yroup }\end{array}$ & Medical masks have a potential role in infrection control \\
\hline Radonovich LJJ:2019 & USA & $\begin{array}{l}\text { To study the effectiveness and differencess of medical masks and } \\
\text { Nas respiriators tor protocting medical staffi in the hospital setting }\end{array}$ & $\begin{array}{l}2862 \mathrm{HCW} \text { s recruited from } 7 \text { medical centers, } 2371 \\
\text { completed the study }\end{array}$ & sted N95 respiriator & dical masks & $\begin{array}{l}\text { Compared with the medical mask group, the infection rate of the N95 respirator group } \\
\text { did not thanges significantly }\end{array}$ & $\begin{array}{l}\text { Nos respirators and medical masks are not significantly different in protecting } \\
\text { outpatient medical staff trom influenzaa }\end{array}$ \\
\hline Simmerman JM,2011 & Thailand & $\begin{array}{l}\text { To examine the effectiveness so non-pharmaceutical interenentions } \\
\text { to reducue influenza transmission }\end{array}$ & 1147 household contacts & Hand sanitizer; surgical face mask; & No facemasks provided & $\begin{array}{l}\text { Compared with the control group, there was no significant difiterence in the incidience of } \\
\text { influenza in the mask roup }\end{array}$ & Hand hygiene and masks do not seem to reduce the spread of influenza \\
\hline Suess T,2012 & Germany & 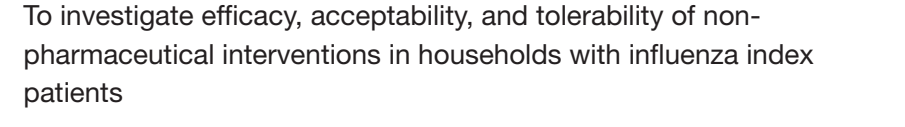 & 218 housenold contacts & $\begin{array}{l}\text { Hand sanitizer and surgical face mask; } \\
\text { surgical face mask }\end{array}$ & b facemasks provided & $\begin{array}{l}\text { Compared with the control group, there was no significant difference in the incidence of } \\
\text { influenza in the mask group }\end{array}$ & $\begin{array}{l}\text { Some interventions, such as mask interventions, may reduce the spread of } \\
\text { influenzzin the tamily }\end{array}$ \\
\hline Thomas F,2011 & USA & To study the impact of wearing masks on radio receppition & 407 crew members & Surgical facemask or N95-Respirator & No facemasks provided & $\begin{array}{l}\text { When the eircrattennine statss, the mask will affect the accuratet transmission and } \\
\text { receppion of some filight terms }\end{array}$ & $\begin{array}{l}\text { the mask maybe affect the accurate transmission and reception of some filight } \\
\text { tems }\end{array}$ \\
\hline Bartoszko, J. J,2020 & Canada & 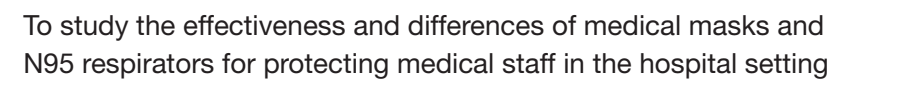 & 5927 HCWs from Canada, China, and USA & N95 respiratators & Medical masks & $\begin{array}{l}\text { Compared with the medical mask group, the infection rate of the N95 respirator group } \\
\text { did not changes significantly }\end{array}$ & 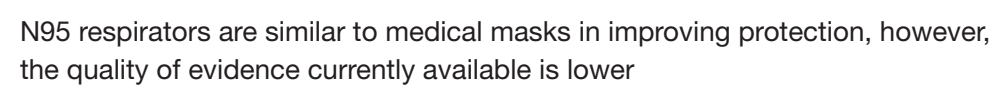 \\
\hline bin-Reza, , 2012 & Sweden & To seek evidence to stop the spread of the pandemic & $\begin{array}{l}4723 \text { participants from Austraila, USA, China, Canada, } \\
\text { and Japan }\end{array}$ & N95 respiriators; surgical masks & urgical masks; no facemasks provided & $\begin{array}{l}\text { Compared with the N95 respiratatr rroup, the incidence of respiratary disease in the } \\
\text { medical mask group was higher }\end{array}$ & $\begin{array}{l}\text { Long-term, continuous use of masks or hand hygiene may be effective for } \\
\text { pandemic control }\end{array}$ \\
\hline Jefferson T,2011 & uk & $\begin{array}{l}\text { To study the effect of physical intervention in blocking the } \\
\text { respiratory virus transmission }\end{array}$ & as from university, $\mathrm{h}$, & $\begin{array}{l}\text { Facemasks Plus Hand Hygiene; } \\
\text { surgical mask group; } \\
\text { P2 mask; N95 respirators }\end{array}$ & acemasks provided; Medical masks & sks aret useftul & $\begin{array}{l}\text { Masks are useful for virus transmission, and N95 respiritotors are better than } \\
\text { medical masks }\end{array}$ \\
\hline Long YL, 2020 & China & $\begin{array}{l}\text { To study the effectiveness and differencese of medical masks and } \\
\text { No5 respiritotors tor protecting medical staff and housenolds }\end{array}$ & 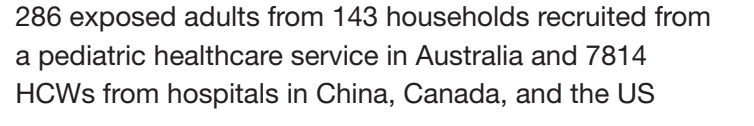 & N95 respirators; P2 mask & gical masks: Lifestyle measures & $\begin{array}{l}\text { Compared with the medical mask group, the infection rate of the N95 respirator group } \\
\text { did not changes iginnificantly }\end{array}$ & N95 respiratotrs are simiarar to medical masks in improvoung protection \\
\hline Offeddu V, 2017 & Singapore & 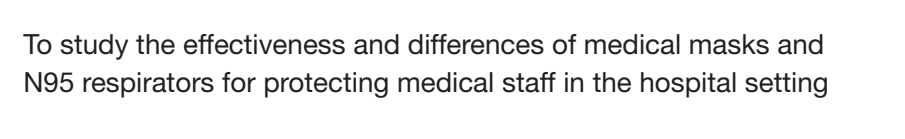 & $\begin{array}{l}5 \text { S1955CWWS in hospitals from China, Japan, Vietnam, and } \\
\text { Canada }\end{array}$ & N95 respirators; medical masks & No facemasks provided; surgical masks & $\begin{array}{l}\text { Compared with the N955 respirator group, the incidence of respiratory disease in the } \\
\text { medical mask group was higher }\end{array}$ & 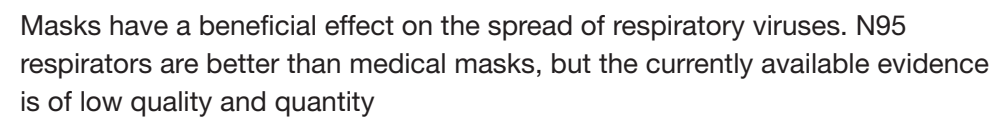 \\
\hline $\begin{array}{l}\text { Saunders-Hastings P, } \\
2017\end{array}$ & Canada & $\begin{array}{l}\text { To examine the effectiveness of personal protedtive measures in } \\
\text { preventing pandemic influenza transmission in humana populations. }\end{array}$ & 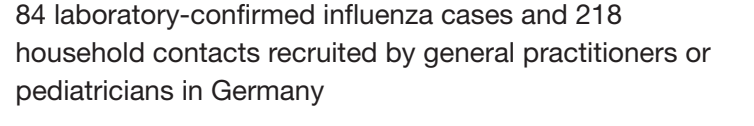 & Sanitizer and face mask; face mask & No facemasks provided & $\begin{array}{l}\text { Facemask use provided a non-significant protective effect against } 2009 \text { pande } \\
\text { influenza i inection }\end{array}$ & $\begin{array}{l}\text { Regular hand hygiene and facemask may be effective at timiting transmission } \\
\text { during future pandemics }\end{array}$ \\
\hline Smith, J. D,2016 & Canada & 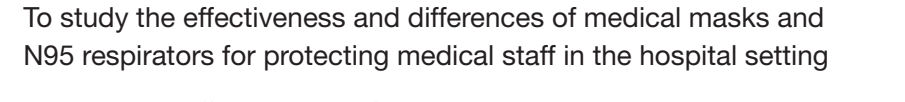 & $3556 \mathrm{HCWs}$ in hospitals from Canada and China & N95 respiriators & Surgical masks & $\begin{array}{l}\text { Compared with the medicaca mask group, the iffection rate of the N95 respirator group } \\
\text { did not changes significanty }\end{array}$ & N95 respirators are similiar to medical masks in improving protection \\
\hline Wong, v. W. Y,2014 & China & $\begin{array}{l}\text { To study the effectiveness of non-1-pharmacocological intetventions } \\
\text { such as masks and hand hygiene in blocking the spread of influenza } \\
\text { in the community }\end{array}$ & $\begin{array}{l}5612 \text { participants come from university, hospital, linics, } \\
\text { housenolds in developed and developing countries }\end{array}$ & 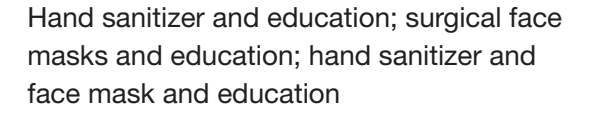 & $\begin{array}{l}\text { No facemasks provided; } \\
\text { heathy diet and lifstyle education }\end{array}$ & $\begin{array}{l}\text { Combined hand hygiene and facemasks showed significant reduction in both laboratory } \\
\text { confirmed influenzza outcomes }\end{array}$ & $\begin{array}{l}\text { Personal inteventions such as masks and hanc hygien are important to stop } \\
\text { the influenza virus }\end{array}$ \\
\hline 20 & China & $\begin{array}{l}\text { To study the effectiveness of personal non-pharmacological } \\
\text { interenotions such as masks and hand hygiene in blocking infuenza } \\
\text { viruses }\end{array}$ & ticipants from Austra & $\begin{array}{l}\text { Facemasks Plus Hand Hyyiene; ;urgical } \\
\text { mask group; P2 mask; N95 respirators }\end{array}$ & education & Rignificant reduction in influenzat transmisssion with the use of fact & $\begin{array}{l}\text { Limitide vevidence on the effectiveness of improved hygiene and environmental } \\
\text { claaning }\end{array}$ \\
\hline
\end{tabular}


Table S4 Quality assessment results for SRs (AMSTAR-2)

\begin{tabular}{|c|c|c|c|c|c|c|c|c|c|c|c|c|c|c|c|c|c|}
\hline Author & Items 1 & Items 2 & Items 3 & Items 4 & Items 5 & Items 6 & Items 7 & Items 8 & Items 9 & Items 10 & Items 11 & Items 12 & Items 13 & Items 14 & Items 15 & Items 16 & Total \\
\hline Bartoszk 2020 & 1 & 1 & 3 & 1 & 1 & 1 & 3 & 1 & 1 & 1 & 1 & 1 & 1 & 3 & 3 & 3 & Moderate quality \\
\hline bin-Reza, 2012 & 1 & 1 & 1 & 1 & 1 & 1 & 3 & 1 & 3 & 3 & 4 & 4 & 3 & 3 & 4 & 1 & Critically Low \\
\hline Jefferson 2011 & 1 & 1 & 1 & 1 & 1 & 1 & 3 & 1 & 2 & 3 & 1 & 1 & 1 & 1 & 1 & 1 & Moderate quality \\
\hline Long, 2020 & 1 & 1 & 1 & 1 & 1 & 1 & 1 & 2 & 1 & 3 & 1 & 1 & 1 & 3 & 3 & 1 & Moderate quality \\
\hline Offeddu, 2017 & 1 & 1 & 1 & 1 & 1 & 1 & 3 & 1 & 2 & 3 & 1 & 1 & 1 & 3 & 1 & 1 & Moderate quality \\
\hline Saunders 2017 & 1 & 1 & 1 & 1 & 1 & 1 & 3 & 2 & 1 & 1 & 1 & 1 & 1 & 1 & 1 & 1 & High quality \\
\hline Smith 2016 & 1 & 1 & 1 & 1 & 1 & 1 & 3 & 2 & 1 & 3 & 1 & 1 & 1 & 3 & 3 & 3 & Moderate quality \\
\hline Wong 2014 & 1 & 1 & 1 & 1 & 1 & 1 & 3 & 3 & 1 & 1 & 1 & 1 & 3 & 3 & 3 & 3 & Critically Low \\
\hline Xiao 2020 & 1 & 2 & 1 & 1 & 1 & 1 & 3 & 1 & 3 & 3 & 1 & 1 & 1 & 1 & 3 & 3 & Critically Low \\
\hline
\end{tabular}

SRs, systematic reviews; AMSTAR-2, Assessment of Multiple Systematic Reviews-2; 1, Yes; 2, Partial Yes; 3, No; 4, No meta-analysis conducted. 